\title{
A review of the bio-tribology of medical devices
}

\author{
Xiaogang ZHANG ${ }^{1}$, Yali ZHANG ${ }^{1}$, Zhongmin JIN $^{1,2,3, *}$ \\ ${ }^{1}$ School of Mechanical Engineering, Southwest Jiaotong University, Chengdu 610031, China \\ ${ }^{2}$ School of Mechanical Engineering, Xi'an Jiaotong University, Xi'an 710049, China \\ ${ }^{3}$ School of Mechanical Engineering, University of Leeds, Leeds LS2 9JT, UK \\ Received: 01 January 2021/Revised: 18 March 2021 /Accepted: 23 March 2021 \\ (C) The author(s) 2021.
}

\begin{abstract}
Numerous medical devices have been applied for the treatment or alleviation of various diseases. Tribological issues widely exist in those medical devices and play vital roles in determining their performance and service life. In this review, the bio-tribological issues involved in commonly used medical devices are identified, including artificial joints, fracture fixation devices, skin-related devices, dental restoration devices, cardiovascular devices, and surgical instruments. The current understanding of the bio-tribological behavior and mechanism involved in those devices is summarized. Recent advances in the improvement of tribological properties are examined. Challenges and future developments for the prospective of bio-tribological performance are highlighted.
\end{abstract}

Keywords: bio-tribology; medical devices; wear; friction

\section{Introduction}

Medical devices have been applied in our daily life for various purposes, such as treatment or alleviation of disease, alleviation of or compensation for injuries, support of the anatomy, or a physiological process [1]. Its global market keeps increasing and reached about $\$ 456.9$ billion in 2019 [2]. Medical devices greatly benefit patients by overcoming sickness and improving life quality. However, they also present a significant inherent potential for hazards. Thus, safety and effectiveness are always the most important considerations before clinical application. When medical devices are used, various interfaces are formed to fulfill particular functions. Such as the articulating interface formed between the femoral and the tibial insert components of an artificial knee joint, the modular interface formed between the head and neck components of an artificial hip joint, the bone tissue-component interface of a dental implant, the interface between artificial limbs and skin, the interface between a stent and the vessel wall, and the interface between organ or tissue of the human body and minimally invasive surgery (MIS) devices. A large proportion of the medical devices' failure is happening on those interfaces, such as the excessive wear of the articulating interface of an artificial joint, loosening and fretting of the implant-bone interface. Thus, the interaction behavior of those interfaces plays a vital role in the safety and effectiveness of medical devices.

The science investigating interacting surfaces is tribology. The term "bio-tribology", introduced by Dowson and Wright, is to investigate the interface behavior and mechanism related to biological systems. Numerous researches have been conducted to investigate the bio-tribological behavior and mechanism of medical devices. Jin et al. [3] reviewed the biotribological issue of selected medical devices. Xie et al. [4] reviewed the bio-tribology of cardiovascular devices. Dawson [5] reviewed bio-tribology with particular emphasis on the development of lubrication. Lanza et al. [6] reviewed the recent advances in the

* Corresponding author: Zhongmin JIN, E-mail: zmjin@swjtu.edu.cn 
bio-tribology of dentistry. Sahoo et al. [7] reported recent advances in the tribological implications of various materials used in biomedical applications. More recently, Meng et al. [8] reviewed the recent advances of tribology, where the advances in the biotribology of joint, dental, and skin were summarized.

Existing investigations reviewed the current understanding of the bio-tribology of medical devices from various points of view, and provide valuable information on the understanding of the bio-tribological behavior and mechanism. However, medical devices have a wide range of applications, and their function principle and mechanism vary a lot. In this review, the tribological issues involved in medical devices are identified, mainly focusing on the recent development up to the last 15 years. The current understanding of the tribological behavior and mechanism involved in the commonly used devices is summarized, including artificial joints, fracture fixation devices, skin-related devices, dental restoration devices, cardiovascular devices, and surgical instruments. Recent advances in the improvement of tribological properties are examined. Challenges and future developments for the prospective of tribological performance are highlighted.

\section{Literature search}

An initial literature search was conducted in Web of Science on $20^{\text {th }}$ October 2020, with the following keywords: Topic $=($ medical device $)$ and (tribology or friction or wear or lubrication). A total record of 9,896 was found. We excluded non-English records, abstract- type documents, and records with publication year before 2005. A total number of 6,747 records remained. However, the keyword "wear" may also mean "have something on one's body". About 3,000 records were identified to be related to wearable devices by additional keywords "wearable, wearing, wore, bodywear, footwear, stockings, mask, head-mounted, patient-worn". Among those wearable records, only 55 records were kept by searching with keywords "friction or lubrication or tribology". Finally, 2,409 records remained and were analyzed in this review. A classification of the records was conducted by medical device types. A total of six types were identified, including artificial joints, dental restoration devices, surgical instruments, skin-related devices, and fracture fixation devices, as shown in Fig. 1. A further classification of the records was conducted by materials, where four main biomaterials were identified including metal, polymer, ceramic, and hydrogel, as shown in Fig. 2. The bio-tribology of the medical devices was reviewed with respect to the six individual medical devices listed in Fig. 1.

\section{Bio-tribology of artificial joints}

\subsection{Bio-tribological issues of artificial joints}

There are about one billion osteoarthritis patients worldwide, and quite a few of them may need a joint replacement. Due to the aging population and the expectation for a more active lifestyle, the demand for joint replacement keeps increasing. Although

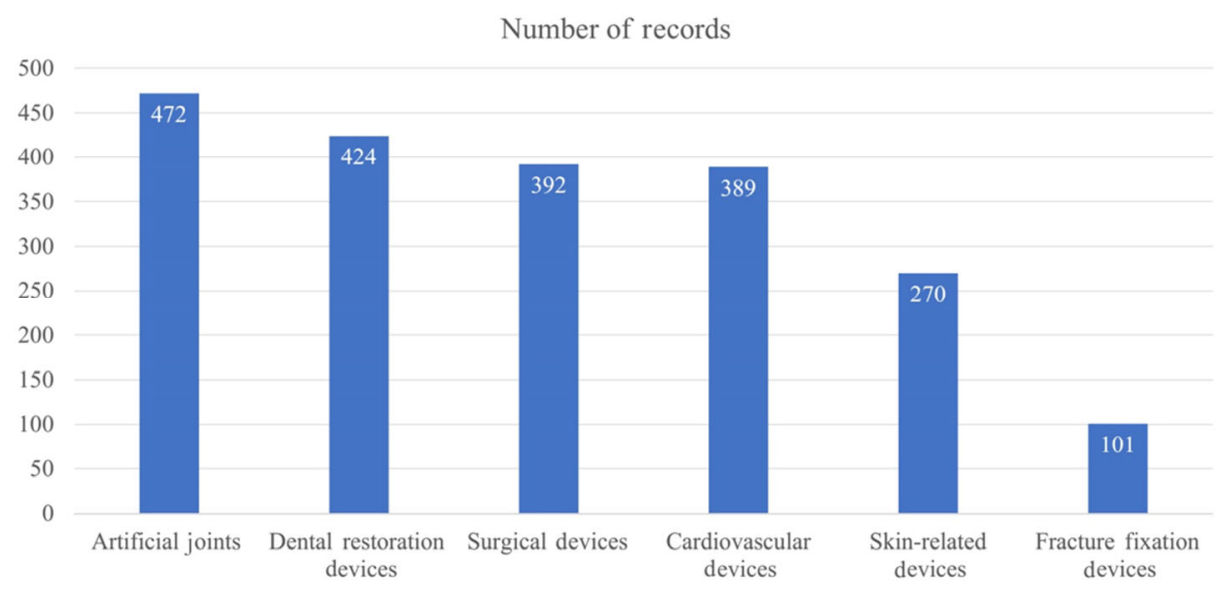

Fig. 1 A classification of the searched medical devices into six types including artificial joints, dental restoration devices, surgical devices, cardiovascular devices, skin-related devices, and fracture fixation devices. 


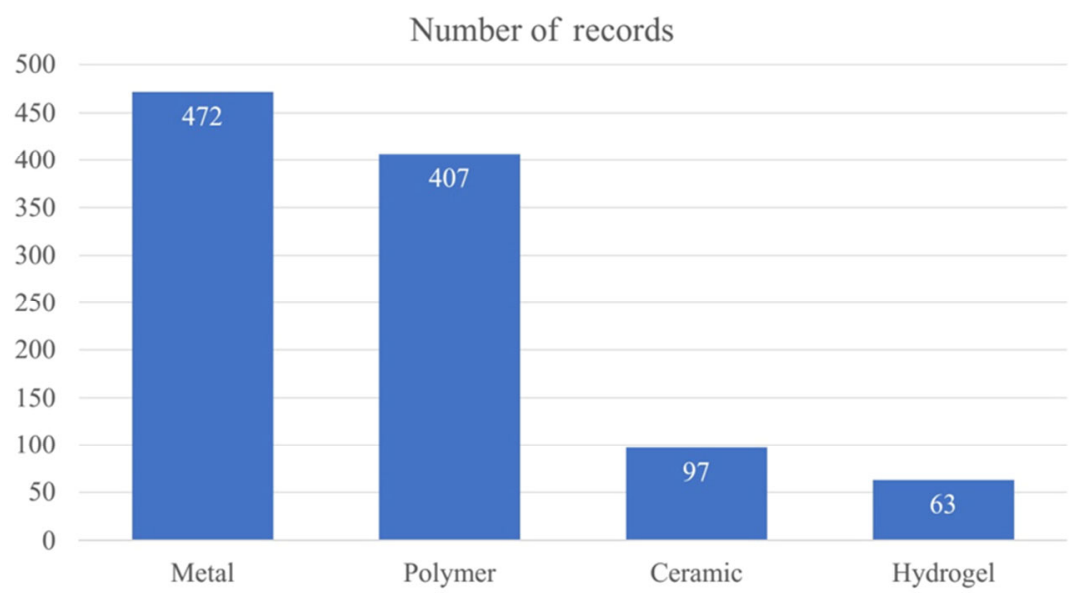

Fig. 2 The number of records in each of the four biomaterials including metal, polymer, ceramic, and hydrogel.

hip and knee replacement currently have the widest application, and various artificial joint replacement technologies have emerged for the development of technology and the accumulation of clinical experience, such as shoulders, elbows, wrists, ankles, fingers, toes, and temporomandibular joints. Joint replacement brings great convenience to the patients, and it has potential risks, among which the tribological failure is an important cause.

Typically, three types of interfaces exist on a typical artificial joint, including the articulating interface, the modular interface, and the fixation interface, as shown in Fig. 3. Articulating interfaces provide relative motion and load-bearing in daily activities. Wear and wear particles due to sliding friction remain the major cause of the revision of artificial hip and knee joints.

A joint is fixed either by press-fit (cementless fixation) or by bone cement (cemented fixation). Aseptic loosening caused by fixation failure is one of the most important indications for revision, and it is especially serious in younger patients [9]. Modular design is

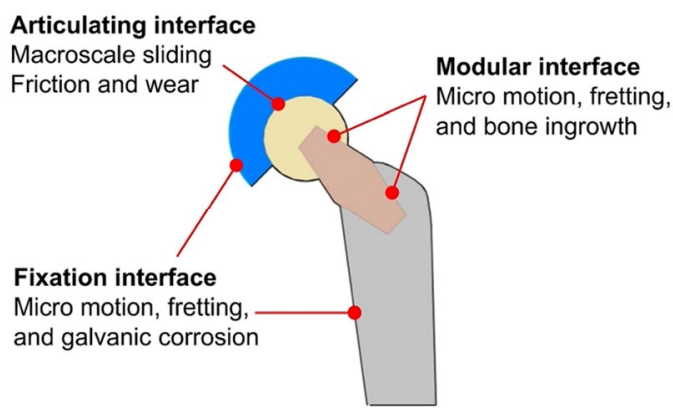

Fig. 3 Illustrations of three interfaces of artificial joints and corresponding tribological mechanism. adopted to promote the application of artificial joints for a wide range of patients. Different modular head and neck combinations of an artificial hip joint can not only restore different anatomical structures but also optimize the biomechanical functions. However, fretting corrosion often happens due to mechanically assisted corrosion [10] and causes the failure of the modular interfaces.

\subsection{Research advances on the bio-tribology of artificial joints}

\subsubsection{Articulating interface}

The articulating interface is designed to provide relative motion. The friction coefficient and wear resistance are important considerations from the perspective of long-term survivorship. However, common complications (such as excessive wear, and aseptic loosening caused by wear particles) due to improper tribological design are the most important factors affecting the performance and long-term effectiveness of artificial joints. Thus, investigation and improvement of the tribological performance of the articulating surface have been one of the main areas in the bio-tribology of artificial joints.

Despite various material combinations are used, the articulating interface can be generally divided into two types, the soft-on-hard, and the hard-on-hard combinations. Due to the excellent tensile strength and impact resistance, ultra-high molecular weight polyethylene (UHMWPE) and its modifications are widely used as the "soft" component. While the "hard" 
component of an articulating pair often includes cobalt-chromium alloys, titanium alloys, stainless steel, alumina, zirconia, and zirconia toughened alumina composite ceramics (ZTA). Since UHMWPE is much softer, it is the major source of wear and wear particles. Figure 4 shows several typical wear features observed from a retrieved acetabular cup [11]. Various approaches have been proposed to improve the wear resistance of UHMWPE. Recent developments include highly cross-linked UHMWPE, which provide substantially improved wear resistance $[12,13]$. The wear rate of irradiated UHMWPE significantly decreased with an increase in the cross-linking gamma irradiation. Also, Vitamin E stabilization is found to protect against the oxidation of cross-linked materials [14].

It's worth noticing that the surface properties of the hard counter-face are also important since its asperities may scratch the soft surface. Various surface coatings of the metallic counter-face are introduced to maintain the low wear of the soft surface. However, the potential long-term durability of the coatings needs further examination [15]. Besides, the design parameters of the articulating surface also play important roles in determining its friction behavior. For example, a large femoral head diameter leads to a larger contact area and a longer sliding distance, which is a disadvantage in terms of wear [16]. However, a larger femoral head may also benefit from hydrodynamic lubrication. Thus, the actual wear performance is a negotiation of design parameters, lubrication, and surgical factors.

There are mainly two types of hard-on-hard combinations for artificial joints, the metal-on-metal, and ceramic-on-ceramic. In vitro experiments indicate that wear in a metal-on-metal articulation is very low due to the improved hydrodynamic lubrication. However, the wear of metal-on-metal is drastically increased under adverse operating conditions due to the breakdown of lubrication film. This is probably the main reason leading to the clinical failure of the device and the drastic reduction in clinical use. Ceramic-on-ceramic has been widely used for artificial knee joints. Compared with metal-on-metal joints, ceramic-on-ceramic joints have higher hardness and scratch resistance, thus it maintains a very low wear rate [17]. However, squeaking, as one of the potential complications, has been reported to happen range from $0.5 \%$ [18] to $10 \%$ [19]. Although various factors have been identified to contribute to squeaking, yet the squeaking mechanism is still unclear. Thus, the complete elimination of the squeaking in ceramic-onceramic joints remains a difficulty. Also, the risk of fracture was reported to be an important concern of
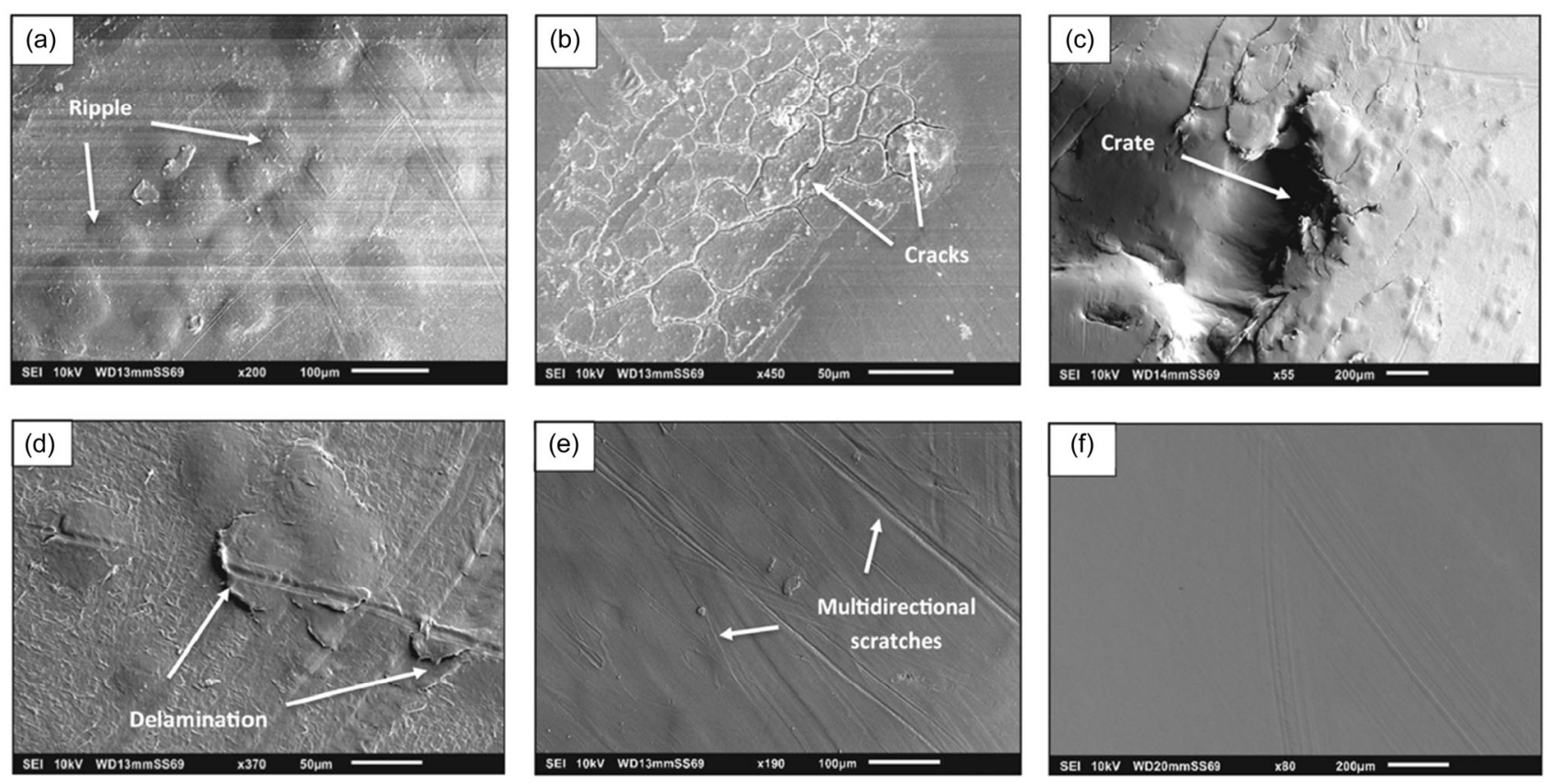

Fig. 4 Illustration of different wear characteristics of UHMWPE acetabular cup. (a) Ripple; (b) crack; (c) crater; (d) delamination; (e) multidirectional scratches; and (f) polished area (fine scratches). Reproduced with permission from Ref. [11], (C) Elsevier B V 2018. 
ceramic-on-ceramic joints. However, with the improved design and manufacturing, the fracture risk of the contemporary ceramic-on-ceramic joints is much lower (0.001\% to $0.021 \%)$ [17].

Researchers have been continuously exploring new bearing surface materials to reduce friction and wear of the articulating interface. Polyether-ether-ketone (PEEK) has been extensively investigated as a potential material to replace UHMWPE due to its prominent biocompatibility, radiation permeability, and other advantages. PEEK has been used in fusion and nonfusion spinal surgery [20-22], as well as semi-rigid fixation [23]. Carbon-fiber-reinforced PEEK (CFR-PEEK) and glass-fiber reinforced PEEK (GFR-PEEK) are demonstrated to have better wear resistance by various experiments [24]. The short-term effectiveness of CFRPEEK as a bearing material for total hip replacement has been validated by preliminary clinical data. However, existing results don't support the clinical advantages of CFR-PEEK over well-established bearing alternatives (such as HXLPE or ceramic acetabular liners) in a traditional total hip design [25]. A new type of polyethylene material, Ultra-low-wear polyethylene (ULWPE), has been reported recently. It has a highly linear structure, narrow molecular weight distribution, and almost no side chains. The wear testing showed excellent wear properties when compared with conventional UHMWPE (as shown in Fig. 5), demonstrating great potential for joint replacement applications [26].

\subsubsection{Fixation interface}

For a long time, fixation failure has been an important cause of revision [27]. Artificial joints are mainly fixed

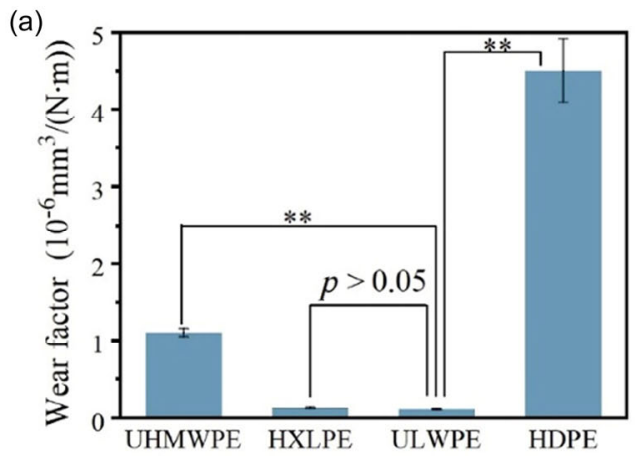

with bone cement or biological fixation. Cemented fixation is realized by using fast-drying bone cement to "glue" the prosthesis and the bone together. The biological fixation is achieved by press-fit, and the prosthesis is specially textured or fabricated in a porous structure to allow bone ingrowth. The optimal fixation, whether cemented fixation or cementless fixation, has been an area of debate for decades.

Bone cement is widely used for its immediate fixation and excellent survivorship. And this is especially true for the knee joints. However, bone cement is prone to interface fretting and fatigue wear, and bone cement debris may cause osteolysis and aseptic loosening. Thus, the long-term stability of the prosthesis-bone interface remains difficult [28]. Due to the biological activity or porous structure of the prosthesis, the biological fixation theoretically provides the possibility to form a safe and reliable long-term fixation, i.e. the host bone grows into the surface or inside of the prosthesis [29]. Because of the better press-fit conditions, biological fixation has been widely used in hip replacements. Uncemented hip joints reduce the prosthesis loosening rate to $1 / 4$, which greatly reduces the revision rate. Despite the excellent survivorship, component long-term fixation remains a concern. Aseptic loosening remains the most common indication for revision [30]. Clinical problems such as sinking [31], fibrous tissue wrapping, and even breakage of the prosthesis were also observed [32, 33], as shown in Fig. 6. Several bio-fixation prostheses of the world's leading companies have been recalled by the United States Food and Drug Administration (US FDA).

Several important factors were reported to affect the fixation stability of the interface. Due to the

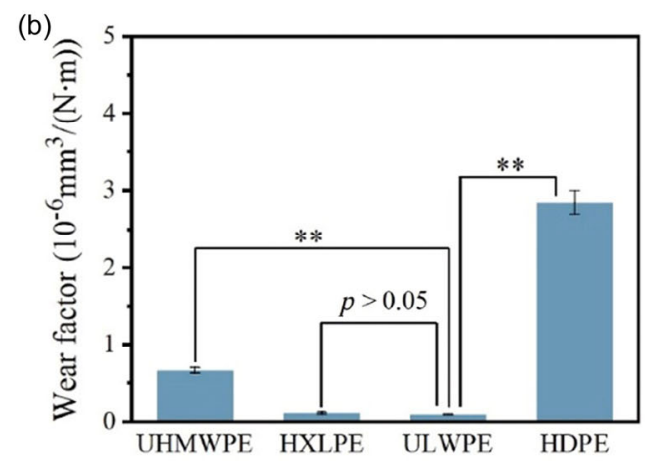

Fig. 5 Comparison of the wear factor of the commonly used polymers for artificial joints applications. Wear factors obtained using different polymer pins on (a) CoCr discs and (b) ZTA discs. Reproduced with permission from Ref. [26], (C) Elsevier B V 2020. 

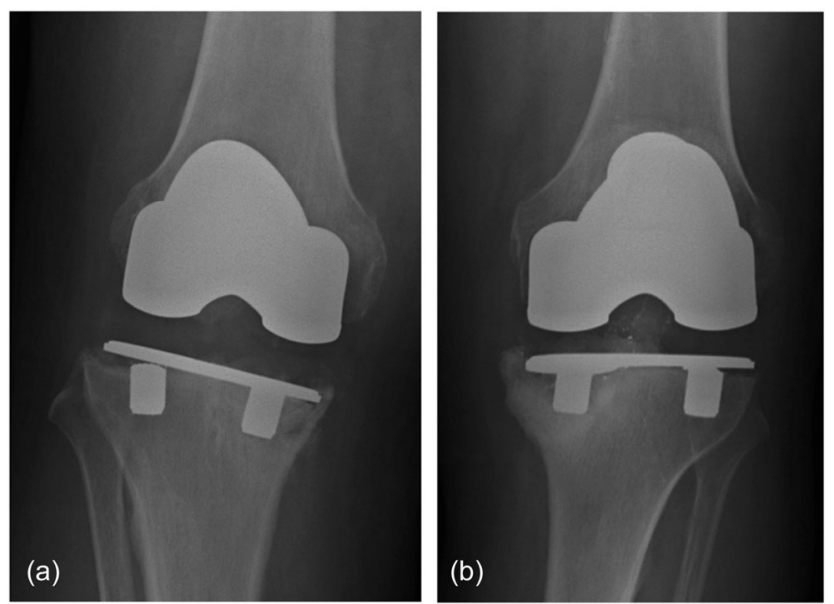

Fig. 6 Failure of tibial fixation. Anteroposterior radiographs of the tibial collapse of (a) patient (a) and (b) patient (b). Reproduced with permission from Ref. [31], (c) Elsevier Inc 2013.

difference in the mechanical properties of metal and natural bone tissue, the strain difference on the interface leads to stress concentration and micro-motion. Small micro-motion allows bone tissue forming, while excessive micro-motion causes the forming of fiber [34]. An increase in the interface gap decreases periimplant tissue forming, bone-implant bind rate, and fixation strength. In addition to the porous material, various factors also play important roles in determining the fixation of a cementless component, such as stiffness, porous structure and topography, and keel or peg design. Early cementless implants had poor survivorship due to design flaws such as using sintered beads or mesh coating, non-continuous fixation [35]. Various investigations have induced promising results in modern cementless designs. The mechanical properties of the porous implant can be tailored to match the stiffness of the local host bone to reduce bone resorption.

\subsubsection{Modular interface}

During daily activities, the articulating interfaces bear three-dimensional dynamic motion and loading. The frictional forces and moments of the articulating interface are transmitted to the modular interfaces, which leads to the fretting of the modular surfaces. In combination with the presence of body fluids, the modular interfaces undergo fretting wear and fretting corrosion. Figure 7 shows typical fretting corrosion damages of retrieved hip components. Similar phenomena also exist in knee joints [36,37], shoulder joints [38], and spinal fixation using assemblies. It is generally believed that fretting corrosion is widespread in various artificial joints.

Modular-neck hips are reported to have a higher revision rate compared to fixed stems [40, 41]. Corrosion and fretting at the taper interface have been widely reported with metal-on-metal and metalon-polyethylene implants [42, 43]. Although the taper corrosion mechanism is not fully understood, a combination of electrochemical and mechanical interactions is identified as important factors [44]. The micromotion between the contact surfaces disrupts the passivation layer, and the exposure of the bulk metal leads to corrosion [45]. Also, crevice corrosion may happen due to the spaces between modular components [46].

Various factors have been related to greater corrosion and/or fretting scores of the taper corrosion such as the femoral head size, surface roughness, femoral
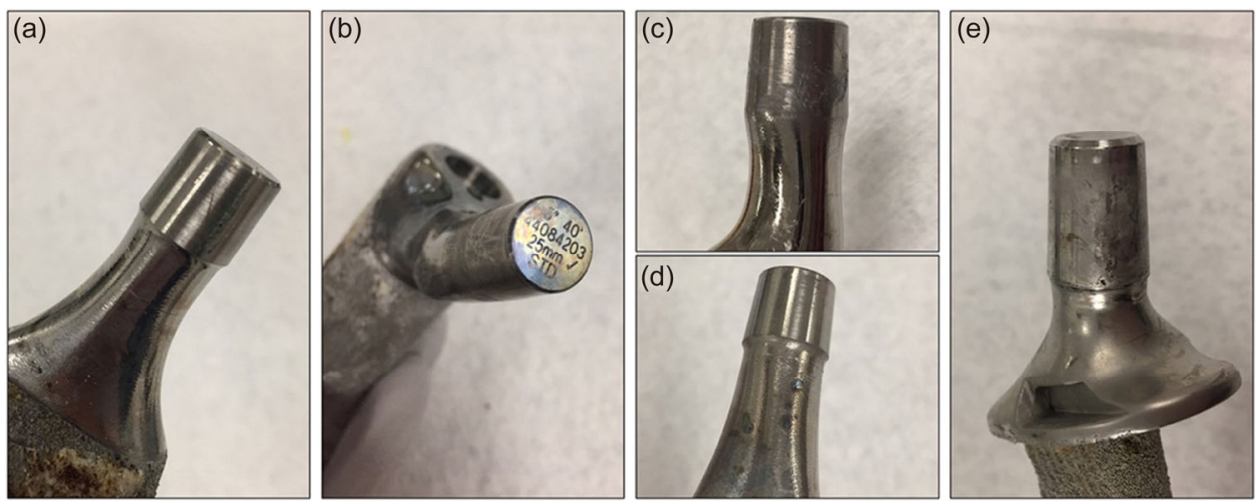

Fig. 7 Fretting corrosion of different grades of damage from retrieved hip components, including none (a), mild (b), moderate (c, d), and severe (e). Reproduced with permission from Ref. [39], (c) Elsevier Inc 2019. 
head-femoral stem offset, and material combinations [47]. Material combinations are one of the important factors for fretting corrosion. Compared with others, the combinations of CoCrMo or stainless steel with titanium alloy have more serious fretting corrosion [48]. The fretting corrosion is relatively light when the ceramic ball head and titanium alloy femoral stem are used. Compared with CoCrMo, the femoral stem using low elastic modulus titanium alloy and ceramic ball joint increases fretting corrosion. While the fretting corrosion is reduced when the PEEK femoral stem is used [49].

Surface coatings were also applied to reduce fretting corrosion. Ceramic coatings have been considered to be an effective approach by reducing galvanic corrosion. However, early attempts failed due to fatigue and delamination caused by their brittle property [50]. Recently, Haschke et al. [51] studied the micromotion reduction effect by the ceramic coating of the taper component, where $\mathrm{SiN}_{x}$ coatings were assumed to improve the corrosion resistance.

The design and manufacturing parameters of the modular interface can also affect the fretting motion. A large diameter of the metal-on-metal bearing surface often results in more serious fretting corrosion [52]. The effects of taper shape on fretting corrosion were studied by Tan et al. [53]. The results showed that the fretting corrosion of a polyethylene/cobalt-chromium alloy assembly with a diameter of $28 \mathrm{~mm}$ is much more serious. Nassif et al. [54] studied the effects of taper designs with different cone angles, slender diameters, and contact lengths on fretting corrosion for the metal-on-metal joints. The investigations show that the taper length has a great influence on the fretting corrosion, and the fretting corrosion increases with an increase in the taper length [55]. However, this result was not confirmed in the study of Higgs et al. [56]. At the same time, researchers also found that adapting different surface morphologies and textures can enhance the fixation of the modular interface [57]. The greater the roughness of the cone, the more serious the fretting corrosion [58]. Besides, the bearing surface between the femoral head and the acetabular cup can also affect the fretting corrosion at the modular interface, and the friction torque at the bearing surface plays an important role in this process. Under adverse conditions, metal-on-metal bearing surfaces with large diameters can produce a high coefficient of friction, leading to severe fretting corrosion $[3,52]$. The weight of the patient can directly affect the fretting corrosion damage at the cone neck assembly [56]. Female patients were identified as a high-risk factor for joint reduction [59], which may be caused by the smaller size of the implant in female patients.

\subsection{Challenges and future work}

The in vivo condition after joint replacement determines the loading of the joint interfaces, thus determining the tribological behavior. However, there are still technical difficulties in the accurate characterization of the in vivo biomechanics of artificial joints. Also, it is often contradictory to satisfy both biomechanical and tribological functions simultaneously. For example, a larger range of motion or better stability may present the interface in worse tribological conditions. Besides, existing investigations of artificial joints focus solely on articular interface wear or fixation stability. Very few studies have considered the coupling effect of the articulating interface and the fixation interface. Furthermore, numerous preliminary experimental results support the clinic application of new materials and coatings. However, their clinical performance needs further validation.

\section{Bio-tribology of fracture fixation devices}

\subsection{Bio-tribological issues of fracture fixation devices}

Bone fracture is a very common body injury. There are millions of fractures worldwide per year, with a global market of $\$ 5.5$ billion [60]. When a bone is broken, a "reduction" orthopedic surgeon is performed to re-set the bone, where various constructs are used for fracture fixation, as shown in Fig. 8. A detailed summary of fracture fixation devices was conducted based on different fracture sites, as shown in Table 1 [61]. Stainless steel, titanium alloys, cobalt-chromium alloys, and NiTi shape-memory alloys are widely used in fracture fixation devices [61]. The interface between the screw and the screw hole of the bone plate produces micro-action, which promotes fretting wear [62]. Also, the screw hole is the weakest link of 


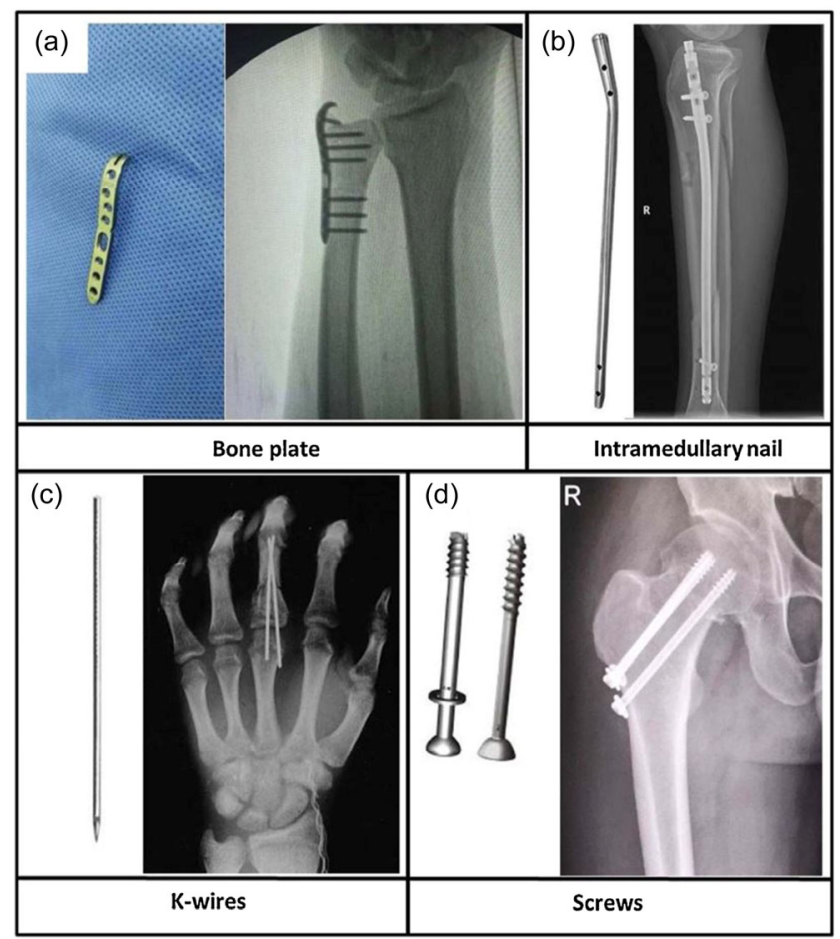

Fig. 8 Common medical devices used for fracture internal fixation. (a) The bone plate used for the fixation of the ulnar fracture; (b) intramedullary nail used for the fixation of tibial fracture; (c) K-wire used for the fixation of the phalangeal fracture; and (d) screws used for the fixation of a femoral neck fracture. Reproduced with permission from Ref. [61], (C) Elsevier B V 2020.

the bone plate. Fatigue fracture often occurs under cycling loading. The micro-motion accelerates the generation of fatigue cracks and causes fatigue damage to the bone plates. Due to the in vivo condition, the synthetic effect of corrosion and fretting may result in unstable and fracture of the constructs. Also, since bone plates are in direct contact with cortical bones, the tribological performance of the bone-fixation plates is of importance for the minimization of wear debris and ion release, which causes inflammation and potentially carcinogenic effects [63].

\subsection{Research advances on the bio-tribology of fracture fixation devices}

The abrasion and corrosion often happen on the joint surface of the screw and the bone plate. The analysis of the clinically broken 316L bone plate also showed serious damage by fretting corrosion. Bartolomeu et al. [64] compared the mechanical and tribological behavior of Ti6Al4V by different processing routes, including conventional casting, hot pressing, and selective laser melting. Their results indicate that selective laser melting produces the highest hardness and wear resistance due to a significantly different microstructure. The in vivo environment of the bonefixation plate interface presents a variety of biological species such as proteins and reactive oxygen species. Those biological species play important roles in determining the fretting corrosion behavior. Zhang

Table 1 Summary of fracture fixation devices. Reproduced with permission from Ref. [61], (c) Elsevier B V 2020.

\begin{tabular}{|c|c|c|}
\hline & Fracture site & Internal fixator \\
\hline \multirow{2}{*}{ Head } & Skull fracture & Wires, pins, and plates \\
\hline & Craniofacial fracture & Wires, screws, and plates \\
\hline \multirow{4}{*}{ Trunk } & Clavicle fracture & Intramedullary nail and plates \\
\hline & Scapular fracture & Screws and plates \\
\hline & Pelvic fracture & Screws, plates, and external fixators \\
\hline & Spinal fracture & The fixation device consists of rods, pedicle screws, and plates \\
\hline \multirow{3}{*}{$\begin{array}{l}\text { Upper limb } \\
\text { fracture }\end{array}$} & Humeral fracture & Open reduction with plate and screws/close reduction with an intramedullary nail \\
\hline & Radius, ulnar fracture & Open reduction with plate and screws/close reduction with an intramedullary nail \\
\hline & $\begin{array}{l}\text { Metacarpal and phalangeal } \\
\text { fracture }\end{array}$ & $\begin{array}{l}\text { Close reduction with external fixators, open reduction with intramedullary nail, } \\
\text { screws, and plates }\end{array}$ \\
\hline \multirow{4}{*}{$\begin{array}{l}\text { Lower limb } \\
\text { fracture }\end{array}$} & Femoral fracture & Open reduction with plate and screws/close reduction with an intramedullary nail \\
\hline & Tibial and fibular fracture & Open reduction with plate and screws and intramedullary nail \\
\hline & Metatarsus fracture & Open reduction with plate and screws and intramedullary nail \\
\hline & Calcaneal fracture & Close reduction and fixation with screws or wires \\
\hline
\end{tabular}


et al. [65] investigated the corrosion behavior of Ti6Al4V in physiological saline with emphasis on the effect of albumin and $\mathrm{H}_{2} \mathrm{O}_{2}$. Their results demonstrate that, in the presence of $\mathrm{H}_{2} \mathrm{O}_{2}$ in physiology saline, albumin suppresses dissolution at short times $(<24 \mathrm{~h})$ but significantly accelerates corrosion over a longer time $(120 \mathrm{~h})$, which is attributed to the thinner oxide film resulted from the albumin-catalyzed dissolution of the corrosion product layer. In addition, the titanium ion release rate is found to be higher at a lower potential. Wang et al. [66] investigated the sliding frictional behaviors of $\mathrm{Ti}-6 \mathrm{Al}-4 \mathrm{~V}$ plates and bovine cortical bone in various bio-lubricants, including physiological saline, simulated body fluids, and fetal bovine serum. They found that the friction pair lubricated by fetal bovine serum shows the largest friction coefficient and wear rate. The presence of the bio-lubricants induces corrosion wear, and the bone wear rate increases with an increase in sliding velocities and normal loads. Various coatings have also been applied to improve the tribological properties of bone plates [67, 68]. Attabi et al. [69] evaluated the tribological behavior of ion nitriding treated Ti6Al4V alloy. Their result indicates that the microhardness is greatly improved and the coefficient of friction was decreased. Wang et al. [70] investigated the wear behavior of the Ti6Al4V bone plate coated with $\mathrm{TiO}_{2}$ nanotubes. Their results demonstrate that the friction coefficient and wear volume were reduced by the coatings, which is attributed to the improvement of the lubrication due to the lower elasticity and higher hydrophilicity. In addition, topology optimization is also an important approach to reduce fretting wear by minimizing the equivalent stiffness of the fixation plates [71]. More recently, Al-Tamimi et al. [63] conducted topology optimization to improve the mechanical, biological, and tribological behavior of fixation plates. Their results demonstrate that significant improvement of biological performance was obtained with acceptable wear resistance.

\subsection{Challenges and future work}

Tribological issues widely exist in fraction fixation components, where several important interactions are involved including biomechanical effects, electrochemical effects, and tribological effects. However, the scope of the research in the area is very limited. Due to the complexity of the in vivo environment, the coupling mechanism hasn't been clearly revealed. In vitro experimental investigations on the improvement of material mechanical and tribological performance have proven to be effective. However, in vivo biomechanical environments of fracture constructs need to be further considered.

\section{Bio-tribology of skin-related devices}

\subsection{Bio-tribological issues of skin-related devices}

Human skin is composed of multi-layers including epidermis, dermis, and hypodermis. Each of the layers is subdivided into different components [72]. Under undesired or excessive loading, a pressure ulcer may occur. A pressure ulcer or pressure sore is a localized injury to the skin and/or underlying tissue under sustained mechanical loading [73]. It is generally observed over a bony prominence in patients with reduced mobility as well as amputees wearing a prosthesis. In particular, about $75 \%$ of those amputees wearing lower-limb prostheses encounter pressure ulcers [74]. Although pressure ulcer is commonly observed, the exact cause and mechanism are still unclear since little work has investigated the skindevice interface [75].

\subsection{Research advances on the bio-tribology of pressure ulcer}

A typical pressure ulcer is considered to be caused by normal and/or shear pressure to the skin. The grade I or II pressure ulcer is considered due to interface shear stress, while the grade III or IV may result from large tissue deformation by normal pressure. Mechanical loading can cause serial changes of local skin tissue such as local ischemia, reperfusion injury, continuous cell deformation, lymphatic drainage, and finally causes tissue damage and pressure ulcer to happen. Generally, sustained pressure loading may cause cytoskeletal structure stress and cell deformation, as well as reduce tissue perfusion and lymphatic flow. Reduced perfusion induces a deficit of nutrients and an accumulation of metabolic wastes. In combination with reduced perfusion, progressive tissue damage 
may finally happen, as shown in Fig. 9.

The mechanism of the mechanical loading-induced pathophysiological response related to tissue damage remains unclear. Studies on the main factors that affect pressure ulcers can be divided into several aspects such as normal pressure loading, shear loading, the surface roughness of the device interface, and microclimate. Pressure ulcer by its name advises that normal pressure is a dominating factor. However, shear loading is also identified as an important factor which accelerates the formation of pressure ulcer. Shear loading is mainly determined by the friction coefficient of device material properties, environmental conditions, and normal load. Existing studies also found that the expression of the IL- $1 \alpha$ cytokine exists a shear stress threshold. An increased expression of the IL- $1 \alpha$ cytokine was observed with an increase in shear stress above the threshold. Thus, patients with high friction devices might be easier to develop pressure ulcers. Although the threshold may vary from one to another, investigations by Klaassen [74] indicate that shear stress smaller than $1.2 \mathrm{kPa}$ and pressure smaller than $2.4 \mathrm{kPa}$ didn't increase the concentration of the IL- $1 \alpha$ cytokine. Such loading might be considered safe for prolonged periods of loading.
The effects of micro-climate and surface roughness are also important factors which influence pressure ulcer by determining the interface friction. The friction coefficient is often lower at lower humidifies, and an increase in humidity causes an immediate increase in the friction coefficient. Skin hydration may be responsible for the interpersonal differences observed in the skin-device friction. Surface roughness is another important factor in determining surface friction. It has a significant influence on the development of pressure ulcers. In the investigations on typical medical device materials such as silicone materials, a minimum coefficient of friction was observed at the Ra roughness of $4 \mu \mathrm{m}$ of the silicone surfaces against an artificial skin [77]. The interface shear stress might be minimized for alleviating or even preventing pressure ulcers.

Strategies to alleviate pressure ulcers are mainly to reduce mechanical loading, especially surface friction. To reduce the skin-device friction, a serial of factors is often considered, such as different materials, surface roughness, and humidity. Using different materials may be effective for pressure ulcer prevention. For example, foam alternatives were found to be more effective than the standard foam mattress in reducing the incidence of pressure ulcers [78]. Synthetic fibers (a)
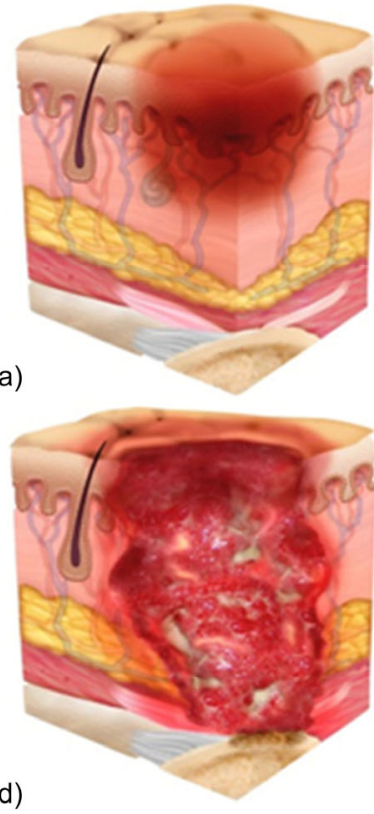

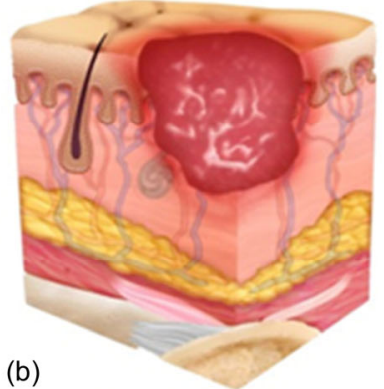

(b)

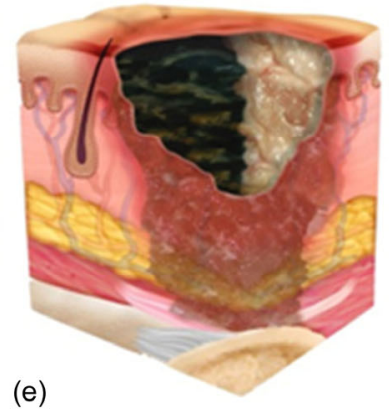

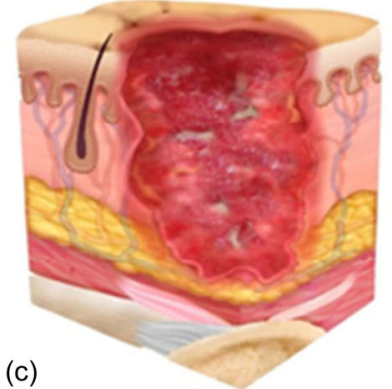

c)

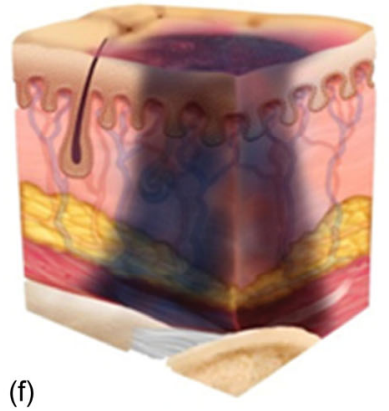

Fig. 9 Different stages of pressure ulcer. (a) Nonblanchable erythema of intact skin; (b) partial-thickness skin loss; (c) full-thickness skin loss; (d) full-thickness skin and tissue loss; (e) unstageable pressure injury; and (f) deep tissue pressure injury. Reproduced with permission from Ref. [76], C Elsevier B V 2019. 
were found to be effective in reducing friction coefficient [79].

\subsection{Challenges and future developments}

Although effective measures have been proposed to reduce pressure-induced skin damage and ulcer, the contributions of different measures and their mechanism need further investigation. To prevent pressure ulcers, a thorough understanding of the skin-device interaction mechanism is required. An obvious measure is to reduce friction to a safe level. However, the friction coefficient cannot be minimized to zero in some cases. Instead, minimal friction is required to stay stable, such as keeping a patient to be sited in an elevated back position. The microenvironment such as humidity and temperature plays important role in the development of the pressure ulcer for the prosthetic socket-stump interface. Future work is expected to further investigate interpersonal differences in the threshold of the combined results of normal and shear pressure under various microenvironment conditions.

\section{Bio-tribology of dental restoration devices}

\subsection{Bio-tribological issues of dental restoration devices}

More and more tribological investigations are conducted on dentistry due to its quick growth and expansion. Based on different applications, the dental restoration tribology is divided into two areas, the

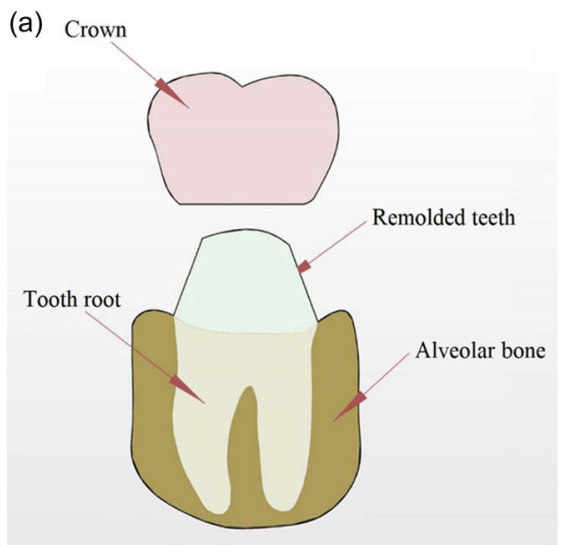

tooth restoration tribology, and dental implant tribology, as shown in Fig. 10. The tooth restoration material is expected to have proper wear resistance. On the one hand, it doesn't wear out during long-term chewing. On the other hand, it is also expected not to wear out its counterpart (natural or restored tooth) during long-term chewing. For a dental implant, fretting corrosion of the modular interface and the fixation stability of the bone-implant interface are the main tribological considerations.

\subsection{Research advances on the bio-tribology of dental restoration devices}

\subsubsection{Tooth restoration devices}

The teeth are exposed to a significant amount of wear during chewing. Thus, the wear resistance of a dental restoration material is of importance. Various types of materials have been used for tooth restoration, including metals and their alloys, polymers, ceramics, and composite-based materials [81].

Since aesthetics is an important consideration of dental restoration, metal and its alloys became depreciated over the years due to their unpleasant color. Only a limited amount of amalgam filling is used as dental restoration materials. The majority of the metals and alloy dental materials are used as orthodontic appliances and dental implants. Polymeric materials are also used for dental restoration, but often demonstrate a high wear rate and poor gloss retention [82]. Dental ceramics are composed of crystalline and glassy phases [83], and their mechanical

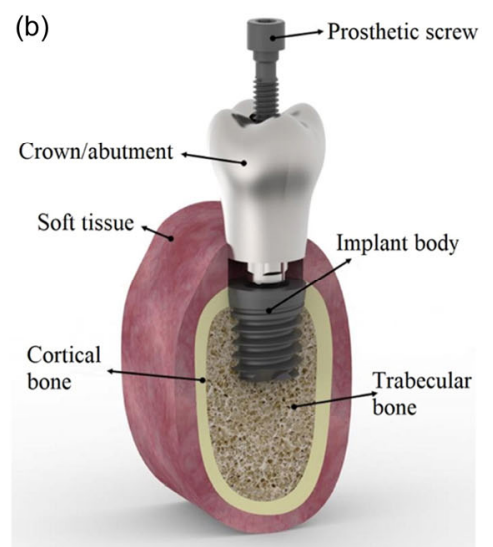

Fig. 10 Dental restoration devices. (a) Tooth restoration and (b) dental implant. Reproduced with permission from Ref. [80]. Reproduced with permission from Ref. [80], C The Authors 2020. 
and tribological properties are closely related to the composition of these two phases. Dental ceramics not only have an appearance close to the natural teeth but also have excellent wear resistance. Thus, they are widely used as restoration materials. One of the disadvantages of dental ceramics is their brittle property, which may cause the failure of the restoration. Compared with natural teeth, the wear resistance of dental ceramics is often higher, which may result in the extensive wear of the opposing occlusal surface of the natural tooth.

Resin-based dental composites consist of organic filler particles (such as Zirconia, borosilicate glass, quartz, and alumina, etc.) in organic monomers such as Bis-GMA (Bisphenol A-glycidyl methacrylate), TEGDMA (Triethylene glycol dimethacrylate), UDMA (Urethane dimethacrylate), HEMA (2-Hydroxyethyl methacrylate), and Bis-EMA (Ethoxylated bisphenolA-dimethacrylate) [84-87]. Materials as such are very close to the characteristics of natural teeth and are frequently employed to restore cavities and replace decayed tooth tissues [88]. Unlike dental ceramics, composite-based materials can be placed through a direct technique, which greatly improves clinical efficiency [89]. Early resin composites demonstrate a high wear rate, since they contain large filler particles. Currently, the wear resistance has been significantly improved by introducing micro/nano-hybrid composites [90]. Kumar et al. [91] studied the wear behavior of Bis-GMA/TEGDMA based composite with different weight fractions of silane-treated nano zirconia particles. Compared with other dental composites, their dental composite filled with $3 \mathrm{wt} \%$ of nano zirconia filler exhibited maximum hardness, minimum wear rate, and outstanding wear resistance. Chadda et al. [92] investigated the fracture toughness and wear behavior of hydroxyapatite and silica/ hydroxyapatite-filled Bis-GMA/TEGDMA composite. The composites with the lowest filler content (20 wt $\%$ ) demonstrate enhanced fracture toughness and moderate wear resistance, and the composites with $30 \mathrm{wt} \%-40 \mathrm{wt} \%$ of filler content exhibit maximum wear resistance.

Ceramic-polymer composites (hybrid ceramics) have both excellent properties of polymers and ceramics, such as high elasticity and ductility, strength, improved translucency, color retention, and wear resistance. The wear resistance of these materials is equivalent to that of feldspar porcelain and glassceramics [93]. Polymer infiltrated ceramic network (PICN) materials provide enhanced mechanical properties and excellent wear resistance. $\mathrm{Xu}$ et al. [94] investigated the wear behavior and mechanism of a PICN material (commercial ENAMIC). They found the ENAMIC has a similar Vickers hardness but lower Young's modulus than tooth enamel. Also, the ENAMIC exhibits a similar wear damage mode to tooth enamel but has lower wear resistance. Yu et al. [95] studied the effect of acidic agents on the wear behavior of a PICN material (Vita Enamic, Vita Zahnfabrik, Bad Sackingen, Germany). Specimens were immersed into different solutions for 4 weeks, including deionized water, $2 \mathrm{wt} \%$ citric acidic solution, $2 \mathrm{wt} \%$ astringent solutions, and $2 \mathrm{wt} \%$ lactic acidic solutions. Reciprocating wear tests were performed under artificial saliva. Their results demonstrate that the acidic environment has limited degradation of the PICN. Although acid erosion demonstrated a significant effect on the initial wear behavior of the PICN, no obvious effect on the long-term wear property was observed.

\subsubsection{Dental implants}

Implants provide a strong foundation for fixed or removable replacement teeth that are made to match natural teeth. There are many advantages to dental implants, including improved appearance, durability, and convenience. However, there are still many failed clinical cases. The possible causes are interface fretting and corrosion $[96,97]$. Although they are difficult to detect, they directly affect the bone ingrowth at the initial stage of implantation and the long-term lifetime of the dental implant [98].

Fretting occurs at the dental implant/bone interface due to the mastication forces. The micro-motion amplitude of the implant needs to be less than a certain threshold to ensure osseointegration. Micro-motions of the implant less than 50 to $150 \mu \mathrm{m}$ are optimal for osseointegration and stability [99]. It is believed that with the development of implantation technology, the simple and uniform upper limit of micromotion amplitude will be replaced by personalized micromotion 
amplitude thresholds, which will be effective by the parameters such as implant materials, surface treatment, and superstructure design.

Pure titanium and its alloy (CP-Ti) are widely used as dental implant materials [100-102]. Compared with conventional dental alloys, however, the tribological properties of $\mathrm{CP}-\mathrm{Ti}$ are poor, although the wear resistance can be improved by alloying [103, 104]. Toxic elements (such as $\mathrm{Al}$ and $\mathrm{V}$ ) are released due to tribo-corrosion. Besides, the elastic modulus of titanium and its alloy is still higher than that of the elastic model of the normal bone, and the stress shielding problem is still prominent. Different alloying elements were selected to improve the tribological properties of CP-Ti. Researchers found that $\beta$ and near- $\beta$ titanium alloys can reduce elastic modulus, but the elastic modulus is still much higher than that of the human bone $[105,106]$. In addition to the usage of alloying elements to improve the wear characteristics, surface modification could also be performed on the implant surface, such as sandblasting [107], etching [108], anodic oxidation [109], and plasma-spraying [110]. The ultrafine-grain pure titanium (UFG-Ti) after sandblasting and acid-etching (SLA) has a hierarchical porous structure on its surface, which exhibits excellent wettability. UFG-Ti has a refined particle size, excellent mechanical properties, and excellent biocompatibility, and has the potential to be used in dental implant materials [111, 112]. PEEK was coated on Ti-6Al-4V due to its higher mechanical properties and wear resistance, which can be used to improve the biocompatibility and wear resistance of the implant [113].

Recently, porous material has been used for dental implants [114]. Porosity effectively improves the coefficient of friction between the implants and surrounding tissues. At the same time, the porosity design can achieve bone ingrowth and osseointegration, which promotes long-term stability [115]. The pore size, shape, and porosity will directly affect the rigid combination of the implant and the new bone tissue. Compared with porous titanium, porous tantalum has better biocompatibility [116]. By surface modification of porous tantalum, the biological activity of porous tantalum can be improved to achieve faster bone ingrowth and more stable bone integration [117].

\subsection{Challenges and future work}

Although the clinical outcomes of dental restoration have been considerably improved due to the improvement of the tribological properties of dental materials, there are still many challenges. Most in vitro studies mainly focus on studying the wear properties of various dental materials. Its long-term in vivo wear mechanism has not been clearly revealed. The lack of research on the wear mechanism of materials may be one of the main obstacles hindering the development of dental materials.

Porous materials have been confirmed to have a larger friction coefficient, and facilitate cell attachment and bone ingrowth. However, how to shorten the time of bone ingrowth and osseointegration through the design of the porous structure (porosity, pore size, etc.) and modification of the porous surface still needs further investigation. The effects of oral microbial environments on porous implants also need to be explored in depth.

\section{Bio-tribology of cardiovascular devices}

\subsection{Bio-tribological issues of cardiovascular devices}

Cardiovascular disease is the leading cause of mortality in the world among non-communicable diseases. Typical cardiovascular disease includes heart valve disease, vascular disease, and coronary artery disease. Various devices are used for cardiovascular diseases, such as heart valves, heart assist devices, and stents. Advances in those devices greatly improved cardiovascular disease therapy during the last several decades. However, tribological problems of cardiovascular devices may cause serious complications (such as hemolysis and thrombus formation) and even failure of the device. Due to the existence of moving components, mechanical wear and friction exist in mechanical heart valves and ventricular assist devices (VAD). The blood flow generates fluid friction on the device-blood interface. This interface should be designed to avoid any blood damage and allow sufficient washouts. In addition, tribology is highly relevant for stents and catheters, since contact with vessels is part of their function. Catheters inevitably interact with vessel walls and may damage the 
endothelium. The deployment of a stent may cause tissue damage. After deployment, the stent migration, due to the unbalanced ratio of friction to hemodynamic force, maybe a major concern.

\subsection{Research advances on the bio-tribology of cardiovascular devices}

Mechanical friction and wear have always been important research interests for various mechanical heart valves [118]. Wear and friction often occur in the hinge region of a bileaflet, between the occluder and the ring or struts in a titling-disc, between the ball and cage in a cage-ball valve [119]. Excessive wear may cause the leaflet to escape or strut fracture, and finally result in the failure of mechanical heart valves. A tribology-related leaflet escape was reported by Zhang et al. [120] in a low profile bileaflet mechanical prosthesis, where excessive wear of the leaflet outflow edge was identified.

Various ventricular assist devices are designed to assist the heart function, including pulsatile pumps and rotary pumps. Various bearing systems are used in ventricular assist devices such as rolling element bearings, pivot bearings [121, 122], and journal bearings. Friction pairs in rolling element bearings don't have direct contact with blood. However, friction heat generation may cause hemolysis in the sealed ball bearings system. Besides, a shaft seal is required to prevent blood from penetrating bearing voids, resulting in bearing seizure. A pivot bearing is often immersed into the blood and is operated under boundary lubrication. Thus, it is required to maintain an adequate blood fluid film to provide sufficient washout. Due to the existence of the fluid shear stress, however, hemolysis may also occur in the blood fluid film [122]. Journal bearings have less wear, but another thrust bearing is often further required which brings complexity. A typical journal bearing uses a blood saline solution to support loads. If a saline solution is used as the bearing fluid, a reservoir and flow cycling line are further required. If the blood is used as the bearing fluid, potential pump seizure by coagulated blood must be carefully considered. Sundareswaran et al. [121] investigated the wear rate of a ball bearing wear by the geometric profile variation obtained by a surface profilometer. The typical bearing wear rate was obtained to be less than $1.46 \mu \mathrm{m} / \mathrm{yr}$. Recently, Da Silva et al. [123] studied the long-term use of the apical aortic blood pump by wear reduction of the bearing components. Their durability test indicates that wear in the lower bearing pivot causes device failure. And a direct correlation between load and wear at the lower bearing pivot was obtained. During the stenting process, as illustrated in Fig. 11 [124], friction at the interface between the stent and blood vessel plays an important role. Endothelium damage is an important cause of the failure by restenosis. The re-reendothelised tissue is often dysfunctional, which may promote in-stent thrombosis and restenosis [125]. After deployment, stent migration and corrosion have
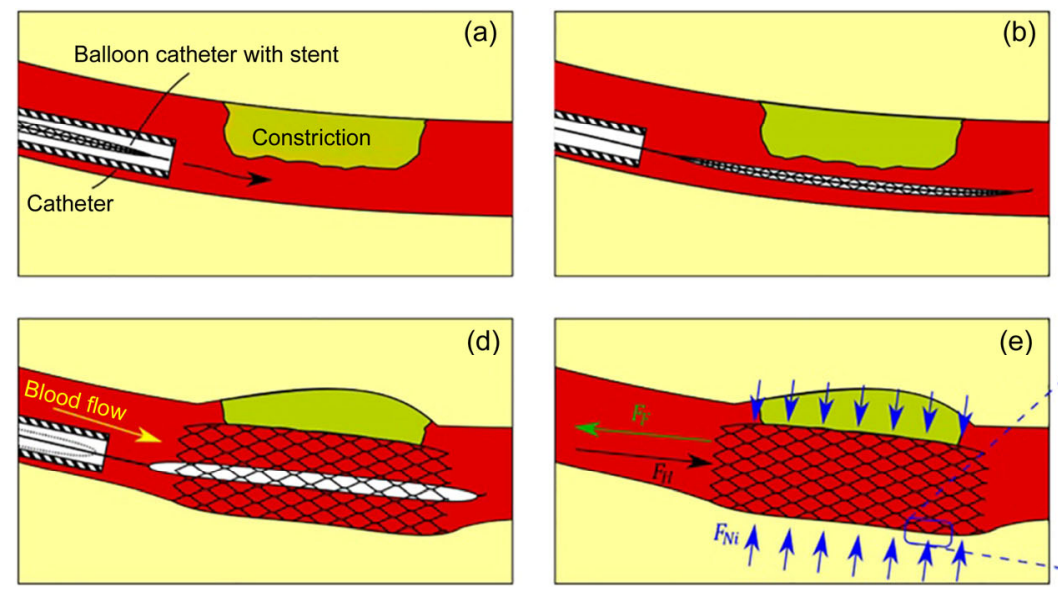

(d)
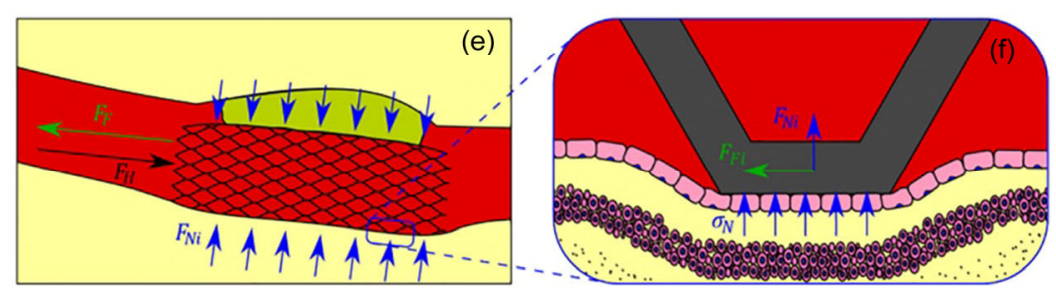

Fig. 11 Illustration of the stenting process. (a) Delivery of catheter and balloon catheter with the stent; (b) the stent is positioned; (c) widening of the stent; (d) deflation of the balloon catheter; (e) forces acting on the stent; and (f) the detailed view of the stent strut. Reproduced with permission from Ref. [124], (c) Elsevier B V 2021. 
been reported to be related to the blood fluid friction [126, 127]. Chen et al. [128] investigated the friction between aortic stent-grafts against porcine aorta, polydimethylsiloxane (PDMS), and polyvinyl alcohol (PVA) cryogels. An average friction coefficient of $0.0328-0.0540$ for a material pairing of porcine aorta/ stent graft sheath was reported. McGee et al. [129] investigated the effect of calcification on tissue-stent interaction. Their results demonstrate that the friction coefficient is significantly increased by calcification from $0.09 \pm 0.05$ up to $0.35 \pm 0.015$. The increasing in the friction coefficient may decrease the stent migration. In addition, in cases such as long or recurrent lesions, two or more stents are required to be deployed. Thus, fretting wearing may occur in the overlapping area of the stents [130].

In the context of the catheter, the frictional interaction between the surfaces on a cellular level should be minimized. Various approaches to lower catheter friction have been proposed such as polymer coating materials, hydrogel coatings, and polymerization. Weiss et al. [131] explored the bio-tribological behavior of short peripheral catheter thrombophlebitis by modeling catheter-vein contact. They revealed that the maximal pressure acted on the vein wall was inhomogeneously distributed, while the bending region was subjected to large deformation and pressure. A potential biomechanical damage pathway was proposed to explain the reoccurrence of short peripheral catheter thrombophlebitis. More recently, Lin et al. [132] studied the tribological behavior of cardiovascular catheters coated with layer-by-layer poly-l-lysine and hyaluronan. Their results demonstrate that poly-l-lysine and hyaluronan coating maintained low friction and prevented wear of endothelial glycocalyx layer. Takahashi et al. [133] studied the effectiveness of preventing peripheral intravenous catheter failure by reducing the mechanical interaction between intravenous catheters and vessels. Their results indicate that the risk of catheter failure can be lowered by reducing the interaction.

\subsection{Challenges and future work}

The research on the bio-tribology of cardiovascular devices is of importance for the prospective of better performance and reliability. However, due to the difficulties of the in vivo visualization and measurement, the in vivo performance hasn't been clearly understood. Future development is expected to construct computational or experimental work that reflects the in vivo behavior. In combination with material and structure optimization of those devices, service performance and life are thus improved. Also, cardiovascular devices may directly interact with blood. Blood lubrication and anticoagulation are also important issues worth noting. Unfortunately, current understandings of the blood lubrication dynamics and biological behavior of blood cells are very limited. Thus, future work is expected to investigate the dynamic interaction between blood cells and device surfaces.

\section{Bio-tribology of minimally invasive surgical devices}

\subsection{Bio-tribological issues of minimally invasive surgical devices}

In recent years, MISs, such as various endoscopic surgeries, are commonly found in medical operations. Tribological problems are accompanied such as needle insertion into a soft tissue, device-tissue interactions, and endoscope-tissue interactions. Due to the existence of the friction and tribological problems between tissue and surgical instruments, it brings difficulties to be able to control the position and force with high precision [134]. There are several factors for the accurate conduction of an MIS, such as needle insertion, grasp, haptic feedback, and transmission hysteresis (by tendon-sheath, cam pulley, etc.). However, the hysteresis is considered a transmission error, which is beyond the scope of bio-tribology and is not discussed here. Only the device-tissue interactions are reviewed.

\subsection{Research advances on the tribology of minimally invasive surgical devices}

\subsubsection{Needle-tissue interaction}

Needle insertion is a commonly performed procedure in various MISs. Friction is an important factor influencing the accuracy of needle insertion. Most 
studies confirm that any increase in the insertion force increases the damage to the tissue. Especially for the brain tissue, even minor damage can cause a longlasting traumatic brain injury. Therefore the medical community has a great demand for innovative minimally invasive needles [135]. A typical needle insertion has four steps, as illustrated in Fig. 12, including 1) the needle tip touches the tissue surface without penetration, 2) the needle penetrates the tissue, 3) the needle holds its position relative to the tissue, and 4) the needle retreats from the tissue [136]. The tribological behavior of needle insertion is of importance in terms of needle placement and path planning.

A large number of researchers have conducted theoretical and experimental analyses on the interaction between the needle and the soft tissue during needle puncture [137-145]. Okamura et al. [146] proposed an empirical puncture force model, which divided the puncture force into three parts, including stiffness force, friction force, cutting force. They also presented methodologies for the measurement of stiffness, friction, cutting forces, and needle geometry effects [146]. Asadian et al. [147] uses a modified LuGre nonlinear model to simulate the acupuncture force. It captures all stages of needle-tissue interaction including puncture, cutting, and friction forces. Associated parameters were also adaptively identified. Roesthuis et al. [148] used a mechanical model to predict the amount of needle deflection for a beveltipped needle inserted into soft tissue. Gao et al. [136] developed a novel algorithm based on an improved local constraint method to simulate the needle-tissue interaction. The needle-tissue forces are assigned to the nodes of both the needle and soft tissue with modified local constraints, which makes the iterative
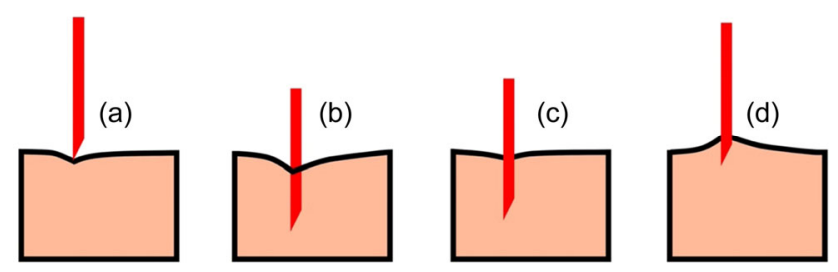

Fig. 12 Four steps of typical needle insertion. (a) Needle tip touches the tissue surface without penetration; (b) needle penetrates the tissue; (c) needle holds its position relative to the tissue; and (d) needle retreats from the tissue. calculation efficient. Although there are various modeling methods available, the accuracy as well as stability of those method still needs to be improved [149].

Experiments have shown that an increase in speed decreases the cutting force and tissue displacement [150-153]. Also, the axial needle rotation affects the penetration force and friction [154-157]. Rotational movement can reduce tissue displacement and friction before puncture. Since biological tissues are generally non-uniform and anisotropic, their mechanical properties depend on position and direction respectively $[158,159]$. Therefore, the position and direction of the insertion are particularly important. Other influence factors on the penetration force have also been investigated including needle tip geometry [160, 161], materials (artificial materials [162, 163], bovine tissue [164-166], pig tissue [167], human tissue [168], etc.), surface texture [169], surface modification [170], and vibration [171].

\subsubsection{Endoscope-tissue interaction}

An endoscopy is conducted by penetrating the endoscopic lens into the body, and then use other surgical instruments and camera display systems to perform operations outside the body. Compared with traditional surgical operations, the functional minimally invasive surgical techniques of medical endoscopes have been widely accepted by doctors and patients due to their advantages such as less pain, short recovery time. During surgical operations, instruments usually need to pass through the mouth, esophagus, or anus to reach the target position. In the process of endoscopic intervention, inspection, and surgery, the instrument may cause certain compression, stretching, and friction damage to the tissue surface, which not only brings great pain to the patient but also causes a series of complicated diseases. Therefore, the research on the tribological properties of the interface is particularly important. The current research methods mainly include finite element analysis and in vitro experimental methods [172, 173]. The digestive tract and the endoscope are usually simplified into a twodimensional axisymmetric structure in finite element models. The digestive tract is often set as a viscoelastic deformable pipe, and the endoscope is set as a smooth 
rigid cylinder. The boundary condition is set to be fixed at both ends. Then, the rigid body slides on the surface of the digestive tract at a certain speed to simulate the relationship between friction and stress distribution in the digestive tract [174]. The in vitro experiment method can be subdivided into two types, the in-tube sliding experiment, and the open sliding experiment, as shown in Fig. 13. Goldbart et al. [175, 176] demonstrated that the addition of small amounts of $\mathrm{MoS}_{2}$ nanoparticles improved the performance of a commercial lubrication gel, reduced the metal-urethra interaction, and alleviated the potential damage to the epithelial tissue. Thiong'o et al. [177] found that the perforations could not be related to shunt catheter stiffness but may be related to greater frictional forces associated with chronic contact of the distal catheter with the intestine.

Researchers have studied the effects of mucus on the interface between the device and the digestive tract. Tribological properties of esophageal tissues with or without trypsin treatment were studied by Li et al. [178]. They found that the mucin can play a lubrication role at the gastroscope device-esophagus interface. However, since the digestive tract was in a straightened state during the experiment, the peristaltic function of the digestive tract was lost after the in vitro experiment, and the open sliding experiment would also destroy the inner surface of the digestive tract.

\subsubsection{Grasper-tissue interaction}

The grasping forceps are matched with the laparoscope,

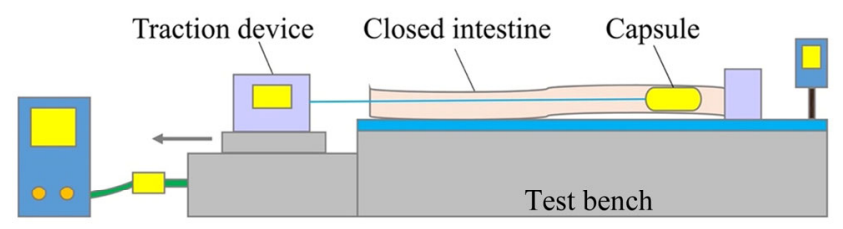

(a) In-tube sliding experiment

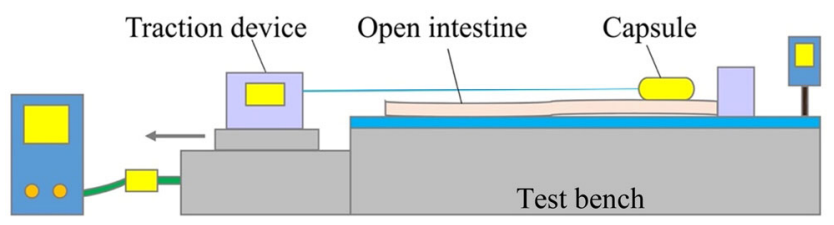

(b) Open sliding experiment

Fig. 13 Schematic of the experimental set-up for the friction at the endoscopy-tissue interface. (a) In-tube sliding experiment and (b) open sliding experiment. which is used for clamping, traction, and fixation of tissues during abdominal surgery in clinical practice. Ideal laparoscopic forceps can grasp tissue stability without damaging the tissue due to excessive grip force. However, because of the small size of laparoscopic instruments, it is easy to produce penetrating stress. About $2 \%-4 \%$ risk of injury to the tissues, such as the bile duct, bowel, vascular structures, is reported during a laparoscopic procedure [179]. Excessive magnitudes of compressive stress exerted on gastrointestinal tissues can lead to pathological scar tissue or adhesion formation, bleeding, inflammation, or even death from bowel perforation and sepsis. This facilitates the optimization of the jaws of the laparoscopic grasper to minimize tissue trauma and maximize grasping force [180].

Usually, the gripper is made of stainless steel, which can be toothed or toothless, or has patterns such as corrugations. High pressures were found to be generated at the tip of laparoscopic graspers, which can be reduced by rounding the edge of the jaw [181]. The laparoscopic graspers modified by refashioning the tip out of silicone (Fig. 14) can reduce the peak tip pressures, particularly at high-load orientations [182]. Vascular clamps showed that force was greater at the proximal end of the clamps, and externally applied handheld clamps showed greater force than internally applied bulldog clamps [183]. Although the improved grasper tips have not been well applied in clinical practice, the above-mentioned research has taken an important step in optimizing the contour of the grasper tip.

Different aspects of instrument jaw geometry have also been investigated. Laparoscopic graspers used

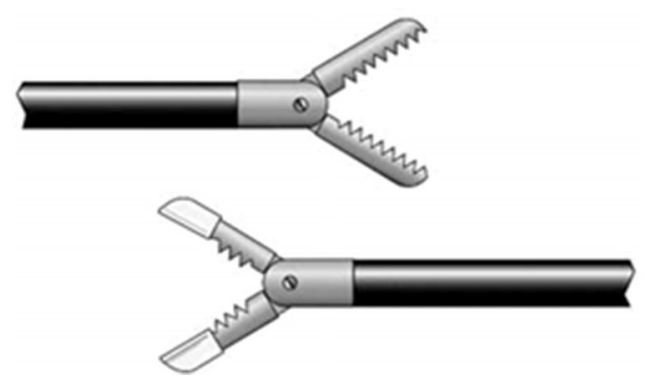

Fig. 14 Two laparoscopic graspers, one of which has been modified to have a compliant edge of silicone. Reproduced with permission from Ref. [182], (C) Wiley-Blackwell Publishing Ltd 2002. 
for manipulating delicate tissue generally possess jaws with fenestrations. However, a fenestration in the jaws increases the local pressures on the tissue because of the reduction of the contact area between jaws and tissue. Fenestrations in the jaws decrease the safe working range of the forceps [184]. Three aspects of jaw geometry including fenestrations, the ratio of the contact surface to fenestration area, and surface profiling had been investigated by Brown et al. [185]. A smooth wave pattern reduced tissue damage, and less tissue damage was minimized with an increasing radius of curvature [186]. Comparing with conventional rigid graspers, soft graspers based on morphing jaws can increase the contact area, thereby reducing the local pressure [187].

\subsection{Challenges and future work}

Existing investigations facilitate the current understanding of the needle-tissue interaction. However, many issues remain to be investigated. A comprehensive analysis of the influencing factors has not yet been conducted. Finite element analysis usually has certain assumptions. Its boundary conditions may be oversimplified. Thus, it may be difficult to simulate the peristalsis and bending of the digestive tract. Besides, most research ignores the influence of liquids such as mucus components or physiological saline on the interaction. The combined effect of multiple factors needs to be continually studied.

The performance of the grasper depends not only on the characteristics of the grasping jaws but also on the force applied by the surgeon. Precise force detection and force feedback technology help to achieve precise grasping force control, which can improve surgical performance and improve surgical quality. Although many researchers have developed several innovative grasping instruments providing haptic feedback of grasping force [188-192], how to obtain and reconstruct force information, and force feedback technology is still a research hotspot.

\section{Summary}

Although great advances have been achieved in the research of bio-tribology of medical devices, there are still issues that need further development. Due to the special application condition, the safety issue is always the most important consideration of medical devices. Although the bio-tribological behavior is observed at the interface, the dynamics effects are often coupled with tribological interactions. The in vivo loading and operating condition of a tribological pair is determined by the bio-system of the human body and its activities. Thus, systematic consideration is especially important. However, the human body and its natural tissue are alive, and it is often difficult to observe the dynamic interaction of natural alive tissue-device interface. The computational approach thus might be proposed to facilitate investigations and simulations of the in vivo behavior of medical devices. Besides, each patient is different from the others. Surgeon and patientspecific factors are also important in terms of the biomechanical environment. For example, height, gender, and bone quality are important considerations for joint replacement. Thus, personalization-related tribological issues are important for the design of medical devices. Developing new materials and surface modification have been widely considered to improve the tribological property, and are proven to be effective. However, tribological behavior is the combined result of the contacting surfaces. Thus, further approaches may consider improving tribological performance by precisely tuning the suitability of the contacting surfaces.

\section{Acknowledgements}

We appreciate the financial supports of the National Natural Science Foundation of China (Nos. 52035012, 52005418, 51905456, and 51775460).

Open Access This article is licensed under a Creative Commons Attribution 4.0 International License, which permits use, sharing, adaptation, distribution and reproduction in any medium or format, as long as you give appropriate credit to the original author(s) and the source, provide a link to the Creative Commons licence, and indicate if changes were made.

The images or other third party material in this article are included in the article's Creative Commons licence, unless indicated otherwise in a credit line to the material. If material is not included in the article's 
Creative Commons licence and your intended use is not permitted by statutory regulation or exceeds the permitted use, you will need to obtain permission directly from the copyright holder.

To view a copy of this licence, visit http://creativecommons.org/licenses/by/4.0/.

\section{References}

[1] Information. https://www.who.int/medical_devices/full_ deffinition/en/, 2020.

[2] Information. https://www.thebusinessresearchcompany.com/ report/medical-devices-market, 2020.

[3] Jin Z M, Zheng J, Li W, Zhou Z R. Tribology of medical devices. Biosurf Biotribol 2(4): 173-192 (2016)

[4] Xie D, Leng Y X, Jing F J, Huang N. A brief review of biotribology in cardiovascular devices. Biosurf Biotribol 1(4): 249-262 (2015)

[5] Dowson D. Bio-tribology. Faraday Discuss 156: 9-30 (2012)

[6] Lanza A, Ruggiero A, Sbordone L. Tribology and dentistry: A commentary. Lubricants 7(6): 52 (2019)

[7] Sahoo P, Das S K, Davim J P. Tribology of materials for biomedical applications. In Mechanical Behaviour of Biomaterials. Davim J P, Ed. San Diego (USA): Woodhead Publishing, 2019: 1-45.

[8] Meng Y G, Xu J, Jin Z M, Prakash B, Hu Y Z. A review of recent advances in tribology. Friction 8(2): 221-300 (2020)

[9] Nam D, Lawrie C M, Salih R, Nahhas C R, Barrack R L, Nunley R M. Cemented versus cementless total knee arthroplasty of the same modern design: A prospective, randomized trial. J Bone Joint Surg Am 101(13): 1185-1192 (2019)

[10] Bingley R, Martin A, Manfredi O, Nejadhamzeeigilani M, Oladokun A, Beadling A R, Siddiqui S, Anderson J, Thompson J, Neville A, et al. Fretting-corrosion at the modular tapers interface: Inspection of standard ASTM F1875-98. Proc Inst Mech Eng, Part H: J Eng Med 232(5): 492-501 (2018)

[11] Shahemi N, Liza S, Abbas A A, Merican A M. Long-term wear failure analysis of uhmwpe acetabular cup in total hip replacement. J Mech Behav Biomed Mater 87: 1-9 (2018)

[12] Popoola O O, Villasenor D A O, Fryman J C, Mimnaugh K, Rufner A. High cycle in vitro hip wear of and in vivo biological response to vitamin $\mathrm{E}$ blended highly crosslinked polyethylene. Biotribology 16: 10-16 (2018)

[13] de Steiger R, Lorimer M, Graves S E. Cross-linked polyethylene for total hip arthroplasty markedly reduces revision surgery at 16 years. J Bone Joint Surg Am 100(15): 1281-1288 (2018)
[14] Saikko V. Wear and friction of thin, large-diameter acetabular liners made from highly cross-linked, vitamin-E-stabilized UHMWPE against CoCr femoral heads. Wear 432-433: 202948 (2019)

[15] Łapaj Ł, Wendland J, Markuszewski J, Mróz A, Wiśniewski T. Retrieval analysis of titanium nitride (TiN) coated prosthetic femoral heads articulating with polyethylene. J Mech Behav Biomed Mater 55: 127-139 (2016)

[16] Sonntag R, Braun S, Al-Salehi L, Reinders J, Mueller U, Kretzer J P. Three-dimensional friction measurement during hip simulation. PLoS One 12(9): e0184043 (2017)

[17] Howard D P, Wall P D H, Fernandez M A, Parsons H, Howard P W. Ceramic-on-ceramic bearing fractures in total hip arthroplasty: An analysis of data from the National Joint Registry. Bone Joint J 99-B(8): 1012-1019 (2017)

[18] Walter W L, Waters T S, Gillies M, Donohoo S, Kurtz S M, Ranawat A S, Hozack W J, Tuke M A. Squeaking hips. $J$ Bone Joint Surg Am 90(Suppl 4): 102-111 (2008)

[19] Cogan A, Nizard R, Sedel L. Occurrence of noise in alumina-on-alumina total hip arthroplasty. A survey on 284 consecutive hips. Orthop Traumatol: Surg Res 97(2): 206-210 (2011)

[20] Siskey R, Ciccarelli L, Lui M K C, Kurtz S M. Are PEEKon-ceramic bearings an option for total disc arthroplasty? An in vitro tribology study. Clin Orthop Relat Res 474(11): 2428-2440 (2016)

[21] Kurtz S M. Development and clinical performance of PEEK intervertebral cages. In PEEK Biomaterials Handbook. Kurtz S M, Ed. 2nd ed. Oxford (UK): William Andrew Publishing, 2019: 263-280.

[22] Kurtz S M, Lanman T. Dynamic stabilization and semirigid PEEK rods for spinal fusion. In PEEK Biomaterials Handbook. Kurtz S M, Ed. 2nd ed. Oxford (UK): William Andrew Publishing, 2019: 281-289.

[23] Lovald S, Berg-Johansen B, Altiok E, Kurtz S M. Polyetheretherketone in trauma. In PEEK Biomaterials Handbook. Kurtz S M, Ed. 2nd ed. Oxford UK: William Andrew Publishing, 2019: 301-317.

[24] Song J, Liao Z H, Shi H Y, Xiang D D, Liu Y H, Liu W Q, Peng Z X. Fretting wear study of PEEK-based composites for bio-implant application. Tribol Lett 65(4): 150 (2017)

[25] Kurtz S M, Nevelos J. PEEK bearing materials for total joint replacement. In PEEK Biomaterials Handbook. Kurtz S M, Ed. 2nd ed. Oxford UK: William Andrew Publishing, 2019: 403-418.

[26] Cui W, Bian Y Y, Zeng H K, Zhang X G, Zhang Y L, Weng X S, Xin S X, Jin Z M. Structural and tribological characteristics of ultra-low-wear polyethylene as artificial 
joint materials. J Mech Behav Biomed Mater 104: 103629 (2020)

[27] Choi Y J, Lee K W, Ha J K, Bae J Y, Lee S K, Kim S B, Seo D K. Comparison of revision rates due to aseptic loosening between high-flex and conventional knee prostheses. Knee Surg Relat Res 30(2): 161-166 (2018)

[28] Hampton C B, Berliner Z P, Nguyen J T, Mendez L, Smith S S, Joseph A D, Padgett D E, Rodriguez J A. Aseptic loosening at the tibia in total knee arthroplasty: A function of cement mantle quality? J Arthroplasty 35(Suppl 6): S190-S196 (2020)

[29] Costales T G, Chapman D M, Dalury D F. The natural history of radiolucencies following uncemented total knee arthroplasty at 9 years. J Arthroplasty 35(1): 127-131 (2020)

[30] Sharkey P F, Lichstein P M, Shen C, Tokarski A T, Parvizi J. Why are total knee arthroplasties failing today-has anything changed after 10 years? J Arthroplasty 29(9): 1774-1778 (2014)

[31] Meneghini R M, de Beaubien B C. Early failure of cementless porous tantalum monoblock tibial components. J Arthroplasty 28(9): 1505-1508 (2013)

[32] Rytter S, Madsen F, Jepsen C F, Stilling M. Implant fracture of the Regenerex ${ }^{\circledR}$ modular metal tibial component: A report of three cases. Knee 26(5): 1143-1151 (2019)

[33] Stormont G, Stormont D. Catastrophic failure of regenerex tibial components: A case series. J Knee Surg 30(6): 594-599 (2017)

[34] Bragdon C R, Burke D, Lowenstein J D, O'Connor A S D, Ramamurti B, Jasty M, Harris W H. Differences in stiffness of the interface between a cementless porous implant and cancellous bone in vivo in dogs due to varying amounts of implant motion. J Arthroplasty 11(8): 945-951 (1996)

[35] Cherian J J, Banerjee S, Kapadia B H, Jauregui J J, Harwin S F, Mont M A. Cementless total knee arthroplasty: A review. J Knee Surg 27(3): 193-198 (2014)

[36] Arnholt C M, Macdonald D W, Malkani A L, Klein G R, Rimnac C M, Kurtz S M, Implant Research Center Writing Committee, Kocagoz S B, Gilbert J L. Corrosion damage and wear mechanisms in long-term retrieved $\mathrm{CoCr}$ femoral components for total knee arthroplasty. J Arthroplasty 31(12): 2900-2906 (2016)

[37] Arnholt C M, MacDonald D W, Tohfafarosh M, Gilbert J L, Rimnac C M, Kurtz S M, Implant Research Center Writing Committee, Klein G, Mont M A, Parvizi J, et al. Mechanically assisted taper corrosion in modular TKA. J Arthroplasty 29(Suppl 9): 205-208 (2014)

[38] Eckert J A, Mueller U, Jaeger S, Panzram B, Kretzer J P. Fretting and corrosion in modular shoulder arthroplasty: A retrieval analysis. BioMed Res Int 2016: 1695906 (2016)
[39] Lombardo D J, Siljander M P, Gehrke C K, Moore D D, Karadsheh M S, Baker E A. Fretting and corrosion damage of retrieved dual-mobility total hip arthroplasty systems. J Arthroplasty 34(6): 1273-1278 (2019)

[40] Colas S, Allalou A, Poichotte A, Piriou P, Dray-Spira R, Zureik M. Exchangeable femoral neck (dual-modular) THA prostheses have poorer survivorship than other designs: A nationwide cohort of 324, 108 patients. Clin Orthop Relat Res 475(8): 2046-2059 (2017)

[41] Di Laura A, Hothi H, Henckel J, Skinner J, Hart A. Should all modular-neck hip implants be banned? Orthop Proc 100-B(Suppl 9): 39 (2018)

[42] Siljander M P, Baker E A, Baker K C, Salisbury M R, Thor $\mathrm{C}$ C, Verner J J. Fretting and corrosion damage in retrieved metal-on-polyethylene modular total hip arthroplasty systems: What is the importance of femoral head size? $J$ Arthroplasty 33(3): 931-938 (2018)

[43] Watanabe H, Takahashi K, Takenouchi K, Sato A, Kawaji $\mathrm{H}$, Nakamura H, Takai S. Pseudotumor and deep venous thrombosis due to crevice corrosion of the head-neck junction in metal-on-polyethylene total hip arthroplasty. $J$ Orthop Sci 20(6): 1142-1147 (2015)

[44] Hui T T, Kubacki G W, Gilbert J L. Voltage and wear debris from $\mathrm{Ti}-6 \mathrm{Al}-4 \mathrm{~V}$ interact to affect cell viability during in-vitro fretting corrosion. J Biomed Mater Res Part A 106(1): 160-167 (2018)

[45] Jacobs J J. Corrosion at the head-neck junction: Why is this happening now? J Arthroplasty 31(7): 1378-1380 (2016)

[46] Swaminathan V, Gilbert J L. Fretting corrosion of CoCrMo and Ti6Al4V interfaces. Biomaterials 33(22): 5487-5503 (2012)

[47] Kurtz S M, Kocagöz S B, Hanzlik J A, Underwood R J, Gilbert J L, MacDonald D W, Lee G C, Mont M A, Kraay $\mathrm{M} J$, Klein G R, et al. Do ceramic femoral heads reduce taper fretting corrosion in hip arthroplasty? A retrieval study. Clin Orthop Relat Res 471(10): 3270-3282 (2013)

[48] Goldberg J R, Gilbert J L, Jacobs J J, Bauer T W, Paprosky W, Leurgans S. A multicenter retrieval study of the taper interfaces of modular hip prostheses. Clin Orthop Relat Res 401: 149-161 (2002)

[49] Nakahara I, Takao M, Bandoh S, Sugano N. Fixation strength of taper connection at head-neck junction in retrieved carbon fiber-reinforced PEEK hip stems. J Artif Organs 17(4): 358-363 (2014)

[50] Osman K, Panagiotidou A P, Khan M, Blunn G, Haddad F $\mathrm{S}$. Corrosion at the head-neck interface of current designs of modular femoral components. Bone Joint $J$ 98-B(5): 579-584 (2016) 
[51] Haschke H, Falkenberg A, Morlock M M, Huber G. Do SiNx coatings bear the potential to reduce the risk of micromotion in modular taper junctions? Proc Inst Mech Eng, Part H: J Eng Med 234(9): 897-908 (2020)

[52] Goldstein Z H, Estrera K, Levine B R. Taper failure after large-diameter metal-on-metal total hip arthroplasty. Orthopedics 39(5): e984-e987 (2016)

[53] Tan S C, Teeter M G, Del Balso C, Howard J L, Lanting B A. Effect of taper design on trunnionosis in metal on polyethylene total hip arthroplasty. J Arthroplasty 30(7): 1269-1272 (2015)

[54] Nassif N A, Nawabi D H, Stoner K, Elpers M, Wright T, Padgett D E. Taper design affects failure of large-head metal-on-metal total hip replacements. Clin Orthop Relat Res 472(2): 564-571 (2014)

[55] Del Balso C, Teeter M G, Tan S C, Lanting B A, Howard J L. Taperosis: Does head length affect fretting and corrosion in total hip arthroplasty? Bone Joint $J$ 97-B(7): 911-916 (2015)

[56] Higgs G B, MacDonald D W, Gilbert J L, Rimnac C M, Kurtz S M, Implant Research Center Writing Committee. Does taper size have an effect on taper damage in retrieved metal-on-polyethylene total hip devices? J Arthroplasty 31(Suppl 9): 277-281 (2016)

[57] Munir S, Walter W L, Walsh W R. Variations in the trunnion surface topography between different commercially available hip replacement stems. J Orthop Res 33(1): 98-105 (2015)

[58] Pourzal R, Hall D J, Ha N Q, Urban R M, Levine B R, Jacobs J J, Lundberg H J. Does surface topography play a role in taper damage in head-neck modular junctions? Clin Orthop Relat Res 474(10): 2232-2242 (2016)

[59] Ghanem E, Ward D M, Robbins C E, Nandi S, Bono J V, Talmo $\mathrm{C}$ T. Corrosion and adverse local tissue reaction in one type of modular neck stem. J Arthroplasty 30(10): 1787-1793 (2015)

[60] Ho-Shui-Ling A, Bolander J, Rustom L E, Johnson A W, Luyten F P, Picart C. Bone regeneration strategies: Engineered scaffolds, bioactive molecules and stem cells current stage and future perspectives. Biomaterials 180: 143-162 (2018)

[61] Li J L, Qin L, Yang K, Ma Z J, Wang Y X, Cheng L L, Zhao D W. Materials evolution of bone plates for internal fixation of bone fractures: A review. J Mater Sci Technol 36: 190-208 (2020)

[62] Nalbantgil D, Tozlu M, Ozdemir F, Oztoprak M O, Arun T. FEM analysis of a new miniplate: Stress distribution on the plate, screws and the bone. Eur J Dent 6(1): 9-15 (2012)

[63] Al-Tamimi A A, Hernandez M A, Omar A, Morales-Aldana D F, Peach C, Bartolo P. Mechanical, biological and tribological behaviour of fixation plates 3D printed by electron beam and selective laser melting. Int J Adv Manuf Technol 109(3): 673-688 (2020)

[64] Bartolomeu F, Buciumeanu M, Pinto E, Alves N, Silva F S, Carvalho O, Miranda G. Wear behavior of Ti6Al4V biomedical alloys processed by selective laser melting, hot pressing and conventional casting. Trans Nonferrous Met Soc China 27(4): 829-838 (2017)

[65] Zhang Y, Addison O, Yu F, Troconis B C R, Scully J R, Davenport A J. Time-dependent enhanced corrosion of $\mathrm{Ti}_{6} \mathrm{Al}_{4} \mathrm{~V}$ in the presence of $\mathrm{H}_{2} \mathrm{O}_{2}$ and albumin. Sci Rep $8(1)$ : 3185 (2018)

[66] Wang C C, Zhang G Q, Li Z P, Zeng X Q, Xu Y, Zhao S C, $\mathrm{Hu} \mathrm{H}$ X, Zhang Y D, Ren T H. Tribological behavior of Ti-6Al-4V against cortical bone in different biolubricants. J Mech Behav Biomed Mater 90: 460-471 (2019)

[67] Hatem A, Lin J L, Wei R H, Torres R D, Laurindo C, de Souza G B, Soares P. Tribocorrosion behavior of low friction TiSiCN nanocomposite coatings deposited on titanium alloy for biomedical applications. Surf Coat Technol 347: 1-12 (2018)

[68] Pana I, Vladescu A, Constantin L R, Sandu I G, Dinu M, Cotrut C M. In vitro corrosion and tribocorrosion performance of biocompatible carbide coatings. Coatings 10(7): 654 (2020)

[69] Attabi S, Mokhtari M, Taibi Y, Abdel-Rahman I, Hafez B, Elmsellem H. Electrochemical and tribological behavior of surface-treated titanium alloy Ti-6Al-4V. J Bio-TriboCorros 5(1): 2 (2019)

[70] Wang G Q, Wang S R, Yang X F, Yu X C, Wen D S, Chang Z Q, Zhang M Y. Fretting wear and mechanical properties of surface-nanostructural titanium alloy bone plate. Surf Coat Technol 405: 126512 (2021)

[71] Al-Tamimi A A, Fernandes P R A, Peach C, Cooper G, Diver C, Bartolo P J. Metallic bone fixation implants: A novel design approach for reducing the stress shielding phenomenon. Virtual Phys Prototyp 12(2): 141-151 (2017)

[72] Limbert G, Masen M A, Pond D, Graham H K, Sherratt M J, Jobanputra R, McBride A. Biotribology of the ageing skin - Why we should care. Biotribology 17: 75-90 (2019)

[73] Secretariat M A. Pressure ulcer prevention: An evidencebased analysis. Ont Health Technol Assess Ser 9(2): 1-104 (2009)

[74] Klaassen M. The static friction behavior of skin with relevance to pressure ulcer prevalence. Ph.D Thesis. Enshurd City (The Netherlands): University of Twente, 2018.

[75] Lenz A L, Johnson K A, Bush T R. A new method to quantify liner deformation within a prosthetic socket for below knee amputees. $J$ Biomech 74: 213-219 (2018) 
[76] Mervis J S, Phillips T J. Pressure ulcers: Pathophysiology, epidemiology, risk factors, presentation. $J$ Am Acad Dermatol 81(4): 881-890 (2019)

[77] Klaassen M, de Vries E G, Masen M A. Friction in the contact between skin and a soft counter material: Effects of hardness and surface finish. J Mech Behav Biomed Mater 92: 137-143 (2019)

[78] McInnes E, Bell-Syer S E, Dumville J C, Legood R, Cullum N A. Support surfaces for pressure ulcer prevention. Cochrane Database Syst Rev 4(4): CD001735 (2008)

[79] Gefen A. The bioengineering theory of the key modes of action of a cyanoacrylate liquid skin protectant. Int Wound J 17(5): 1396-1404 (2020)

[80] Armentia M, Abasolo M, Coria I, Albizuri J. Fatigue design of dental implant assemblies: A nominal stress approach. Metals 10(6): 744 (2020)

[81] Carvalho A, Pinto P, Madeira S, Silva F S, Carvalho O, Gomes J R. Tribological characterization of dental restorative materials. Biotribology 23: 100140 (2020)

[82] Mörmann W H, Stawarczyk B, Ender A, Sener B, Attin T, Mehl A. Wear characteristics of current aesthetic dental restorative $\mathrm{CAD} / \mathrm{CAM}$ materials: Two-body wear, gloss retention, roughness and Martens hardness. J Mech Behav Biomed Mater 20: 113-125 (2013)

[83] Shenoy A, Shenoy N. Dental ceramics: An update. J Conserv Dent 13(4): 195-203 (2010)

[84] Arsecularatne J A, Chung N R, Hoffman M. An in vitro study of the wear behaviour of dental composites. Biosurf Biotribol 2(3): 102-113 (2016)

[85] El Zhawi H, Kaizer M R, Chughtai A, Moraes R R, Zhang Y. Polymer infiltrated ceramic network structures for resistance to fatigue fracture and wear. Dent Mater 32(11): 1352-1361 (2016)

[86] Pratap B, Gupta R K, Bhardwaj B, Nag M. Resin based restorative dental materials: Characteristics and future perspectives. Jpn Dent Sci Rev 55(1): 126-138 (2019)

[87] Pratap B, Gupta R K, Shekhawat D S, Yadav A, Chaabra D, Nag M. Physical and mechanical characterization of nanoalumina filled resin based dental composites. Mater Today: Proc 28: 2171-2173 (2020)

[88] Kruzic J J, Arsecularatne J A, Tanaka C B, Hoffman M J, Cesar P F. Recent advances in understanding the fatigue and wear behavior of dental composites and ceramics. $J$ Mech Behav Biomed Mater 88: 504-533 (2018)

[89] Nedeljkovic I, Teughels W, De Munck J, Van Meerbeek B, Van Landuyt K L. Is secondary caries with composites a material-based problem? Dent Mate 31(11): e247-e277 (2015)
[90] Yadav S, Gangwar S. A critical evaluation of tribological interaction for restorative materials in dentistry. Int J Polym Mater Polym Biomater 68(17): 1005-1019 (2019)

[91] Kumar S R, Patnaik A, Bhat I K. The in vitro wear behavior of nanozirconia-filled dental composite in food slurry condition. Proc Inst Mech Eng, Part J: J Eng Tribology 231(1): 23-40 (2016)

[92] Chadda H, Satapathy B K, Patnaik A, Ray A R. Mechanistic interpretations of fracture toughness and correlations to wear behavior of hydroxyapatite and silica/hydroxyapatite filled bis-GMA/TEGDMA micro/hybrid dental restorative composites. Compos Part B: Eng 130: 132-146 (2017)

[93] Choi J W, Song E J, Shin J H, Jeong T S, Huh J B. In vitro investigation of wear of CAD/CAM polymeric materials against primary teeth. Materials 10(12): 1410 (2017)

[94] Xu Z, Yu P, Arola D D, Min J, Gao S S. A comparative study on the wear behavior of a polymer infiltrated ceramic network (PICN) material and tooth enamel. Dent Mater 33(12): 1351-1361 (2017)

[95] Yu P, Xu Z, Arola D D, Min J, Zhao P, Gao S S. Effect of acidic agents on the wear behavior of a polymer infiltrated ceramic network (PICN) material. J Mech Behav Biomed Mater 74: 154-163 (2017)

[96] Corne P, De March P, Cleymand F, Geringer J. Frettingcorrosion behavior on dental implant connection in human saliva. J Mech Behav Biomed Mater 94: 86-92 (2019)

[97] Alfaro M F, Rossman P K, da Silva Viera Marques I, Dube A, Takoudis C, Shokuhfar T, Mathew M T, Sukotjo C. Interface damage in titanium dental implant due to tribocorrosion: The role of mastication frequencies. $J$ BioTribo-Corros 5(4): 81 (2019)

[98] Apaza-Bedoya K, Tarce M, Benfatti C A M, Henriques B, Mathew M T, Teughels W, Souza J C M. Synergistic interactions between corrosion and wear at titanium-based dental implant connections: A scoping review. J Periodontal Res 52(6): 946-954 (2017)

[99] Lioubavina-Hack N, Lang N P, Karring T. Significance of primary stability for osseointegration of dental implants. Clin Oral Implants Res 17(3): 244-250 (2006)

[100] Liu X T, Chen S Y, Tsoi J K H, Matinlinna J P. Binary titanium alloys as dental implant materials - a review. Regen Biomater 4(5): 315-323 (2017)

[101] Khodaei M, Nejatidanesh F, Shirani M J, Iyengar S, Sina H, Valanezhad A, Savabi O. Optimum temperature and chlorine ion concentration for hydrogen peroxide treatment of titanium dental implant material. J Mater Res Technol 9(6): 13312-13319 (2020)

[102] Bosshardt D D, Chappuis V, Buser D. Osseointegration of 
titanium, titanium alloy and zirconia dental implants: Current knowledge and open questions. Periodontology 2000 73(1): 22-40 (2017)

[103] Hussein M A, Suryanarayana C, Arumugam M K, AlAqeeli N. Effect of sintering parameters on microstructure, mechanical properties and electrochemical behavior of $\mathrm{Nb}-\mathrm{Zr}$ alloy for biomedical applications. Mater Des $\mathbf{8 3}$ : 344-351 (2015)

[104] Liu R, Tang Y L, Zeng L L, Zhao Y, Ma Z, Sun Z Q, Xiang L B, Ren L, Yang K. In vitro and in vivo studies of anti-bacterial copper-bearing titanium alloy for dental application. Dent Mater 34(8): 1112-1126 (2018)

[105] Lan C B, Wu Y, Guo L L, Chen H J, Chen F. Microstructure, texture evolution and mechanical properties of cold rolled Ti-32.5Nb-6.8Zr-2.7Sn biomedical beta titanium alloy. J Mater Sci Technol 34(5): 788-792 (2018)

[106] Yan L M, Yuan Y W, Ouyang L J, Li H, Mirzasadeghi A, Li L. Improved mechanical properties of the new Ti-15Ta- $x \mathrm{Zr}$ alloys fabricated by selective laser melting for biomedical application. J Alloys Compd 688: 156-162 (2016)

[107] Yabutsuka T, Mizuno H, Takai S. Fabrication of bioactive titanium and its alloys by combination of doubled sandblasting process and alkaline simulated body fluid treatment. J Ceram Soc Japan 127(10): 669-677 (2019)

[108] Liu X, Niu Y M, Xie W L, Wei D Q, Du Q. Comparative investigations of in vitro and in vivo bioactivity of titanium vs. $\mathrm{Ti}-24 \mathrm{Nb}-4 \mathrm{Zr}-8 \mathrm{Sn}$ alloy before and after sandblasting and acid etching. $R S C A d v$ 10(40): 23582-23591 (2020)

[109] Khodaei M, Alizadeh A, Hosseini H R M. Effect of oxidizing atmosphere on the surface of titanium dental implant material. J Bionic Eng 16(6): 1052-1060 (2019)

[110] Wang F F, Li C J, Zhang S, Liu H C. Tantalum coated on titanium dioxide nanotubes by plasma spraying enhances cytocompatibility for dental implants. Surf Coat Technol 382: 125161 (2020)

[111] An B L, Li Z R, Diao X O, Xin H T, Zhang Q, Jia X R, $\mathrm{Wu}$ Y L, Li K, Guo Y Z. In vitro and in vivo studies of ultrafine-grain Ti as dental implant material processed by ECAP. Mater Sci Eng: C 67: 34-41 (2016)

[112] Medvedev A E, Molotnikov A, Lapovok R, Zeller R, Berner S, Habersetzer P, Torre F D. Microstructure and mechanical properties of $\mathrm{Ti}-15 \mathrm{Zr}$ alloy used as dental implant material. J Mech Behav Biomed Mater 62: 384-398 (2016)

[113] Kruk A, Zimowski S, Łukaszczyk A, Cieniek Ł, Moskalewicz T. The influence of heat treatment on the microstructure, surface topography and selected properties of PEEK coatings electrophoretically deposited on the Ti-6Al-4V alloy. Prog Org Coat 133: 180-190 (2019)

[114] Pałka K, Pokrowiecki R. Porous titanium implants: A review. Adv Eng Mater 20(5): 1700648 (2018)

[115] Bose S, Banerjee D, Shivaram A, Tarafder S, Bandyopadhyay A. Calcium phosphate coated $3 \mathrm{D}$ printed porous titanium with nanoscale surface modification for orthopedic and dental applications. Mater Des 151: 102-112 (2018)

[116] Edelmann A R, Patel D, Allen R K, Gibson C J, Best A M, Bencharit S. Retrospective analysis of porous tantalum trabecular metal-enhanced titanium dental implants. $J$ Prosthet Dent 121(3): 404-410 (2019)

[117] Kuo T Y, Chin W H, Chien C S, Hsieh Y H. Mechanical and biological properties of graded porous tantalum coatings deposited on titanium alloy implants by vacuum plasma spraying. Surf Coat Technol 372: 399-409 (2019)

[118] Zhao D F, Seco M, Wu J J, Edelman J B, Wilson M K, Vallely M P, Byrom M J, Bannon P G. Mechanical versus bioprosthetic aortic valve replacement in middle-aged adults: A systematic review and meta-analysis. Ann Thorac Surg 102(1): 315-327 (2016)

[119] Zilla P, Brink J, Human P, Bezuidenhout D. Prosthetic heart valves: Catering for the few. Biomaterials 29(4): 385-406 (2008)

[120] Zhang H B, Deng X Y, Cianciulli T F, Zhang Z, Chappard D, Lax J A, Saccheri M C, Redruello H J, Jordana J L, Prezioso $\mathrm{H}$ A, et al. Pivoting system fracture in a bileaflet mechanical valve: A case report. $J$ Biomed Mate Res Part B Appl Biomater 90B(2): 952-961 (2009)

[121] Sundareswaran K S, Reichenbach S H, Masterson K B, Butler K C, Farrar D J. Low bearing wear in explanted HeartMate II left ventricular assist devices after chronic clinical support. ASAIO J 59(1): 41-45 (2013)

[122] Moazami N, Fukamachi K, Kobayashi M, Smedira N G, Hoercher K J, Massiello A, Lee S, Horvath D J, Starling R C. Axial and centrifugal continuous-flow rotary pumps: A translation from pump mechanics to clinical practice. J Heart Lung Transplant 32(1): 1-11 (2013)

[123] da Silva B U, da Fonseca J W G, Leal E B, Cardoso J R, Biscegli J F, de Andrade A J P. Apical aortic blood pump preclinical assessment for long-term use: Durability test and stator topology to reduce wear in the bearing system. Artif Organs 44(8): 779-784 (2020)

[124] Wagner R M F, Maiti R, Carré M J, Perrault C M, Evans P C, Lewis R. Bio-tribology of vascular devices: A review of tissue/device friction research. Biotribology 25: 100169 (2021)

[125] Cornelissen A, Vogt F J. The effects of stenting on 
coronary endothelium from a molecular biological view: Time for improvement? J Cell Mol Med 23(1): 39-46 (2019)

[126] Krsmanovic D, Koncar I, Petrovic D, Milasinovic D, Davidovic L, Filipovic N. Computer modelling of maximal displacement forces in endoluminal thoracic aortic stent graft. Comput Methods Biomech Biomed Engin 17(9): 1012-1020 (2014)

[127] Wang J, Giridharan V, Shanov V, Xu Z G, Collins B, White L, Jang Y, Sankar J, Huang N, Yun Y. Flow-induced corrosion behavior of absorbable magnesium-based stents. Acta Biomater 10(12): 5213-5223 (2014)

[128] Chen T H, Lancaster M, Lin D S Y, Doyle M G, Forbes T $\mathrm{L}$, Amon $\mathrm{C} \mathrm{H}$. Measurement of frictional properties of aortic stent grafts and their delivery systems. J Med Devices 13(2): 021008 (2019)

[129] McGee O M, Sun W, McNamara L M. An in vitro model quantifying the effect of calcification on the tissue-stent interaction in a stenosed aortic root. J Biomech 82: 109-115 (2019)

[130] Kapnisis K K, Halwani D O, Brott B C, Anderson P G, Lemons J E, Anayiotos A S. Stent overlapping and geometric curvature influence the structural integrity and surface characteristics of coronary nitinol stents. $J$ Mech Behav Biomed Mater 20: 227-236 (2013)

[131] Weiss D, Gefen A, Einav S. Modelling catheter-vein biomechanical interactions during an intravenous procedure. Comput Methods Biomech Biomed Eng 19(3): 330-339 (2016)

[132] Lin C X, Wan H P, Kaper H J, Sharma P K. A hyaluronic acid based lubricious coating for cardiovascular catheters. Tribol Int 151: 106495 (2020)

[133] Takahashi T, Murayama R, Abe-Doi M, Miyahara-Kaneko M, Kanno C, Nakamura M, Mizuno M, Komiyama C, Sanada H. Preventing peripheral intravenous catheter failure by reducing mechanical irritation. Sci Rep 10(1): 1550 (2020)

[134] Mohammadzadegan A F, Ashrafzadeh F, Moodi H. Hybrid force and position control of a 4DOF surgical robot with disturbance observer. In Proceedings of 2019 27th Iranian Conference on Electrical Engineering, Yazd, Iran, 2019: 1052-1057.

[135] Sahlabadi M, Khodaei S, Jezler K, Hutapea P. Insertion mechanics of bioinspired needles into soft tissues. Minim Invasive Ther Allied Technol 27(5): 284-291 (2018)

[136] Gao D D, Lei Y, Lian B, Yao B. Modeling and simulation of flexible needle insertion into soft tissue using modified local constraints. J Manuf Sci Eng 138(12): 121012 (2016)
[137] Abolhassani N, Patel R, Moallem M. Needle insertion into soft tissue: A survey. Med Eng Phys 29(4): 413-431 (2007)

[138] Tan L, Jones J A, Barnett A C, Zhang H, Moore J Z, Zhang Q. Force model for ultrasonic needle insertion. Exp Tech 42(5): 499-508 (2018)

[139] Ramezanpour H, Yousefi H, Rezaei M, Rostami M. Effects of rotational motion in robotic needle insertion. J Biomed Phys Eng 5(4): 207-216 (2015)

[140] DiMaio S P, Salcudean S E. Interactive simulation of needle insertion models. IEEE Trans Biomed Eng 52(7): 1167-1179 (2005)

[141] Rossa C, Lehmann T, Sloboda R, Usmani N, Tavakoli M. A data-driven soft sensor for needle deflection in heterogeneous tissue using just-in-time modelling. Med Biol Eng Comput 55(8): 1401-1414 (2017)

[142] Rajeswari N R, Malliga P. Analytical approach for optimization design of MEMS based microneedles in drug delivery system. J Mech Sc Technol 29(8): 3405-3415 (2015)

[143] Chentanez N, Alterovitz R, Ritchie D, Cho L, Hauser K K, Goldberg K, Shewchuk J R, O'Brien J F. Interactive simulation of surgical needle insertion and steering. $A C M$ Trans Graph 28(3): 88 (2009)

[144] Mo Z L, Mao X J, Hicks K O, Xu W L. In-vivo tissue identification on mice using a fiber optical tip force sensing needle. IEEE Sens J 18(15): 6352-6359 (2018)

[145] Elgezua I, Kobayashi Y, Fujie M G. Estimation of needle tissue interaction based on non-linear elastic modulus and friction force patterns. In Proceedings of 2014 IEEE/RSJ International Conference on Intelligent Robots and Systems, Chicago, USA, 2014: 4315-4320.

[146] Okamura A M, Simone C, O’Leary M D. Force modeling for needle insertion into soft tissue. IEEE Trans Biomed Eng 51(10): 1707-1716 (2004)

[147] Asadian A, Kermani M R, Patel R V. A compact dynamic force model for needle-tissue interaction. In Proceedings of 2010 Annual International Conference of the IEEE Engineering in Medicine and Biology, Buenos Aires, Argentina, 2010: 2292-2295.

[148] Roesthuis R J, Van Veen Y R J, Jahya A, Misra S. Mechanics of needle-tissue interaction. In Proceedings of 2011 IEEE/RSJ International Conference on Intelligent Robots and Systems, San Francisco, USA, 2011: 2557-2563.

[149] Yang C J, Xie Y, Liu S, Sun D. Force modeling, identification, feedback control of robot-assisted needle insertion: A survey of the literature. Sensors 18(2): 561 (2018) 
[150] Mahvash M, Dupont P E. Mechanics of dynamic needle insertion into a biological material. IEEE Trans Biomed Eng 57(4): 934-943 (2010)

[151] Chen H C, Shaw J S, Lee J F, Wu S F. Study on fast needle puncture to reduce pain. In Proceedings of 2019 IEEE International Conference on Architecture, Construction, Environment and Hydraulics, Xiamen, China, 2019: 128-132.

[152] Khadem M, Rossa C, Sloboda R S, Usmani N, Tavakoli M. Mechanics of tissue cutting during needle insertion in biological tissue. IEEE Robot Autom Lett 1(2): 800-807 (2016)

[153] Mahvash M, Dupont P E. Fast needle insertion to minimize tissue deformation and damage. In Proceedings of 2009 IEEE International Conference on Robotics and Automation, Kobe, Japan, 2009: 3097-3102.

[154] Tsumura R, Takishita Y, Fukushima Y, Iwata H. Histological evaluation of tissue damage caused by rotational needle insertion. In Proceedings of 2016 38th Annual International Conference of the IEEE Engineering in Medicine and Biology Society, Orlando, USA, 2016: 5120-5123.

[155] Abolhassani N, Patel R V, Ayazi F. Minimization of needle deflection in robot-assisted percutaneous therapy. Int J Med Robot Comput Assist Surg 3(2): 140-148 (2007)

[156] Zwimpfer T A, Fellmann-Fischer B, Oehler R, Schötzau A, Kind A B. A crossover study on the advantage of an additional rotation function in a needle holder compared to a conventional needle holder in a pelvitrainer model. Laparosc Surg 4(10): 1-9 (2020)

[157] Yen C J. Huang Y A, Lin C L. Using simulation to study cutting force in biopsy needle insertion with bi-directional rotation. J Mech Med Biol 19(2): 1940020 (2019)

[158] Tsumura R, Shitashima K, Iwata H. Insertion method for minimizing fine needle deflection in bowel insertion based on experimental analysis. In Proceedings of 2017 IEEE/RSJ International Conference on Intelligent Robots and Systems, Vancouver, Canada, 2017: 187-192.

[159] Wang Y, Fu Z, Zhao Z F, Shen Y, Zhang T F, Shi W Y, Fei J, Chen G B. Experimental study of the optimum puncture pattern of robot-assisted needle insertion into hyperelastic materials. Proc Inst Mech Eng, Part H: J Eng Med 235(1): 28-43 (2021)

[160] Moore J Z, Zhang Q H, McGill C S, Zheng H J, McLaughlin P W, Shih A J. Modeling cutting edge geometry for plane and curved needle tips. Proc Inst Mech Eng, Part B: J Eng Manuf 226(5): 861-869 (2012)

[161] Lee J, Wang J, Park W. Efficient mechanism design and systematic operation planning for tube-wire flexible needles.
$J$ Mech Robot 10(6): 065001 (2018)

[162] Dehghan E, Wen X, Zahiri-Azar R, Marchal M, Salcudean $\mathrm{S}$ E. Modeling of needle-tissue interaction using ultrasoundbased motion estimation. Med Image Comput Comput Assist Interv, 10(Pt 1): 709-716 (2007)

[163] Sprang T, Breedveld P, Dodou D. Wasp-inspired needle insertion with low net push force. In Proceedings of the 5th Conference on Biomimetic and Biohybrid Systems, Edinburgh, UK, 2016: 307-318.

[164] Moore J Z, Malukhin K, Shih A J, Ehmann K F. Hollow needle tissue insertion force model. CIRP Ann 60(1): 157-160 (2011)

[165] Moore J Z, Shih A J. Tissue oblique cutting flow angle and needle insertion contact length. Trans NAMRI/SME 38: 711-718 (2010)

[166] Moore J Z, McLaughlin P W, Shih A J. Novel needle cutting edge geometry for end-cut biopsy. Med Phys 39(1): 99-108 (2012)

[167] Wang Y C, Chen R K, Tai B L, Xu K, Shih A J. Study of insertion force and deformation for suturing with precurved NiTi guidewire. J Biomech Eng 137(4): 041004 (2015)

[168] Præstmark K A, Jensen M L, Madsen N B, Kildegaard J, Stallknecht B M. Pen needle design influences ease of insertion, pain, skin trauma in subjects with type 2 diabetes. BMJ Open Diabetes Res Care 4(1): e000266 (2016)

[169] Patel D S, Singh A, Jain V K, Ramkumar J, Shrivastava A. Investigations into insertion force of electrochemically micro-textured hypodermic needles. Int $J$ Adv Manuf Technol 100(5-8): 1311-1326 (2019)

[170] Kasem H, Shriki H, Ganon L, Mizrahi M, Abd-Rbo K, Domb A J. Rubber plunger surface texturing for friction reduction in medical syringes. Friction 7(4): 351-358 (2019)

[171] Gidde S T R, Ciuciu A, Devaravar N, Doracio R, Kianzad $K$, Hutapea P. Effect of vibration on insertion force and deflection of bioinspired needle in tissues. Bioinspir Biomim 15(5): 054001 (2020)

[172] Arata J, Kogiso S, Sakaguchi M, Nakadate R, Oguri S, Uemura M, Byunghyun C, Akahoshi T, Ikeda T, Hashizume M. Articulated minimally invasive surgical instrument based on compliant mechanism. Int J Comput Assist Radiol Surg 10(11): 1837-1843 (2015)

[173] Sun Y Y, Liu H B, Wang S X, Back J, Zuo S Y, Bernth J E, Zhang G K, Wang G H, Li J M. A variable-dimension overtube for natural orifice transluminal endoscopic surgery. IEEE Access 8: 42720-42733 (2020)

[174] Gao M Y, Hu C Z, Chen Z Z, Zhang H H, Liu S. Design and fabrication of a magnetic propulsion system for self- 
propelled capsule endoscope. IEEE Trans Biomed Eng 57(12): 2891-2902 (2010)

[175] Goldbart O, Elianov O, Shumalinsky D, Lobik L, Cytron S, Rosentsveig R, Wagner H D, Tenne R. Study of urological devices coated with fullerene-like nanoparticles. Nanoscale 5(18): 8526-8532 (2013)

[176] Goldbart O, Sedova A, Yadgarov L, Rosentsveig R, Shumalinsky D, Lobik L, Wagner H D, Tenne R. Lubricating medical devices with fullerene-like nanoparticles. Tribol Lett 55(1): 103-109 (2014)

[177] Thiong'o G M, Luzzio C, Albright A L. Ventriculoperitoneal shunt perforations of the gastrointestinal tract. J Neurosurg Pediatr 16(1): 36-41 (2015)

[178] Lin C X, Liu W, Xie J Y, Li W, Zhou Z R. The lubricating function of mucin at the gastroscope device-esophagus interface. Tribol Lett 68(3): 82 (2020)

[179] Sammour T, Kahokehr A, Srinivasa S, Bissett I P, Hill A G. Laparoscopic colorectal surgery is associated with a higher intraoperative complication rate than open surgery. Ann Surg 253(1): 35-43 (2011)

[180] Barrie J. Next generation of atraumatic laparoscopic instruments through analysis of the instrument-tissue interface. Ph.D Thesis. Leeds (UK): University of Leeds, 2017.

[181] Bos J, Doornebosch E W L J, Engbers J G, Nyhuis O, Dodou D. Methods for reducing peak pressure in laparoscopic grasping. Proc Inst Mech Eng Part, H: J Eng Med 227(12): 1292-1300 (2013)

[182] Marucci D D, Cartmill J A, Martin C J, Walsh W R. A compliant tip reduces the peak pressure of laparoscopic graspers. ANZ J Surg 72(7): 476-478 (2002)

[183] Lee H J, Box G N, Abraham J B A, Elchico E R, Panah R A, Taylor M B, Moskowitz R, Deane L A, McDougall E M, Clayman R V. Laboratory evaluation of laparoscopic vascular clamps using a load-cell device-are all clamps the same? J Urol 180(4): 1267-1272 (2008)

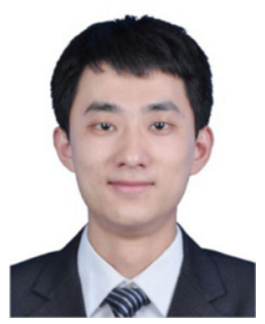

Xiaogang ZHANG. He received his Ph.D. degree in mechanical engineering in 2017 from The University of New South Wales, Australia. He joined the Tribology
[184] Heijnsdijk E A M, Kragten G A, Mugge W, Dankelman J, Gouma D J. Fenestrations in the jaws of laparoscopic graspers. Minim Invasive Ther Allied Technol 14(1): 45-48 (2005)

[185] Brown A W, Brown S I, Mclean D, Wang Z G, Cuschieri A. Impact of fenestrations and surface profiling on the holding of tissue by parallel occlusion laparoscopic graspers. Surg Endosc 28(4): 1277-1283 (2014)

[186] Cheng L, Hannaford B. Evaluation of liver tissue damage and grasp stability using finite element analysis. Comput Methods Biomech Biomed Eng 19(1): 31-40 (2016)

[187] Wils K S, Devasahayam S R, Manivannan M, Mathew G. Force model for laparoscopic graspers: implications for virtual simulator design. Minima Invasive Ther Allied Technol 26(2): 97-103 (2017)

[188] Sakaguchi Y, Sato T, Yutaka Y, Muranishi Y, Komatsu T, Yoshizawa A, Nakajima N, Nakamura T, Date $H$. Development of novel force-limiting grasping forceps with a simple mechanism. European $J$ Cardio-Thorac Surg 54(6): 1004-1012 (2018)

[189] Xue R F, Du Z J, Yan Z Y, Ren B Y. An estimation method of grasping force for laparoscope surgical robot based on the model of a cable-pulley system. Mech Mach Theory 134: 440-454 (2019)

[190] Li C S, Gu X Y, Ren H L. A cable-driven flexible robotic grasper with lego-like modular and reconfigurable joints. IEEE/ASME Trans Mech 22(6): 2757-2767 (2017)

[191] Ly H H, Tanaka Y, Fukuda T, Sano A. Grasper having tactile sensing function using acoustic reflection for laparoscopic surgery. Int J Comput Assist Radiol Surg 12(8): 1333-1343 (2017)

[192] Alleblas C C J, Vleugels M P H, Stommel M W J, Nieboer T E. Performance of a haptic feedback grasper in laparoscopic surgery: A randomized pilot comparison with conventional graspers in a porcine model. Surg Innov 26(5): 573-580 (2019)

Research Institute at Southwest Jiaotong University as an assistant researcher in 2018. His current research interests focus on the musculoskeletal biomechanics and biotribology. 


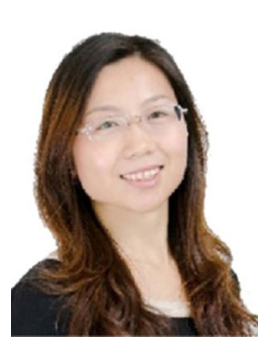

Yali ZHANG. She received her Ph.D. degree in mechanical engineering in 2013 from Xi'an Jiaotong University, China. She joined the

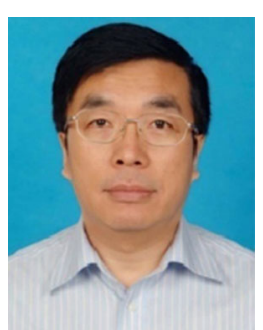

Zhongmin JIN. He received his Ph.D. degree in mechanical engineering in 1984 from University of Leeds, UK. He joined the School of Mechanical Engineering at Southwest Jiaotong University (SWJTU) from
School of Mechanical Engineering at Southwest Jiaotong University as a lecturer in 2015. Her current research interests focus on the biotribology of artificial joints.

2015. His current position is a professor and the dean of the SWJTU-Leeds Joint School. His current research interests include biotribology, biomechanics and medical devices, artificial joint design and manufacturing, and tissue engineering. 